\title{
La caída de las exportaciones industriales a Brasil, ¿cuánto afectó a la producción argentina?*
}

\author{
Marta Bekerman ** \\ Federico Dulcich ${ }^{* * *}$ \\ Pedro Gaite ${ }^{* * * * *}$
}

\section{Resumen}

Brasil ha jugado históricamente un rol fundamental como destino de las exportaciones industriales argentinas. A partir de 2014 las importaciones brasileras han comenzado a disminuir, perjudicadas por la recesión económica, lo que afectó marcadamente a las exportaciones industriales argentinas a ese país. En ese contexto, este trabajo se orienta a analizar hasta qué punto ese impacto afectó a los niveles de producción de la industria argentina. Para el período 2011-2016 se pudo determinar que, al generar el sector industrial alrededor del $80 \%$ de las exportaciones totales a Brasil, la merma en las exportaciones de dicho sector explica el 22\% de la caída en la producción industrial. A nivel desagregado, las ramas que muestran el mayor impacto son la automotriz y la fabricación de productos químicos, seguidos por papel, instrumental médico y maquinaria y equipos eléctricos.

Palaras clave: Exportaciones; Argentina; Brasil; Producción industrial; Estructura productiva.

\section{Resumo}

Queda das exportações industriais para o Brasil. Quanto afetou a produção argentina?

O Brasil tem desempenhado historicamente um papel fundamental como destino das exportações industriais argentinas. A partir de 2014, as importações brasileiras começaram a diminuir, prejudicadas pela recessão econômica, e isso afetou marcadamente as exportações industriais argentinas para esse país. Neste contexto, o trabalho orienta-se a analisar até que ponto esse impacto afetou os níveis de produção da indústria argentina. Para o período 2011-2016 foi possível determinar que, tendo o setor industrial gerando por volta de $80 \%$ das exportações totais para o Brasil, a diminuição na exportação deste setor explica $22 \%$ da queda na produção industrial. Em nível desagregado, as áreas que mostram maior impacto pertencem ao setor automotriz e de fabricação de produtos químicos, vindo logo depois o setor de papel, instrumental médico e maquinário e equipamentos elétricos.

Palavras-chave: Exportações; Argentina; Brasil; Produção industrial; Estrutura produtiva.

* Artículo recibido el 5 de abril de 2018 y aprobado el 30 de enero de 2020.

** Directora del Centro de Estudios de la Estructura Económica (CENES) de la Facultad de Ciencias Económicas de la Universidad de Buenos Aires (FCE. UBA), Buenos Aires, Argentina. E-mail: marbekerman@gmail.com. ORCID: https://orcid.org/0000-0002-5815-8375.

${ }^{* * *}$ Investigador del Centro de Estudios de la Estructura Económica (CENES) de la Facultad de Ciencias Económicas de la Universidad de Buenos Aires (FCE. UBA), Buenos Aires, Argentina. E-mail: federicomd2001@gmail.com. ORCID: https://orcid.org/0000-0002-3375-1906.

**** Investigador del Centro de Estudios de la Estructura Económica (CENES) de la Facultad de Ciencias Económicas de la Universidad de Buenos Aires (FCE. UBA), Buenos Aires, Argentina. E-mail: gaitepedro@gmail.com. ORCID: https://orcid.org/0000-0002-4173-7223. 


\begin{abstract}
The fall in industrial exports to Brazil: how much was Argentine production affected?

Brazil has historically played a fundamental role in receiving Argentinian industrial exports. In 2014, Brazilian imports began to fall as a result of the economic recession, a fact that strongly affected the industrial exports to Brazil. In this context, the objective of this work is to analyze the impact that the fall in exports to Brazil has had on the Argentine industrial production. For the period 2011-2016, as the industrial exports accounted for near $80 \%$ of total exports to Brazil, the fall in the sector's exports represented a reduction of $22 \%$ in industrial production. At a disaggregated level, the branches that show the greatest impact are the automotive sector and the manufacture of chemical products, followed by paper, medical instruments and electrical machinery and instruments.
\end{abstract}

Keywords: Exports; Argentina; Brazil; Industrial production; Industrial branches; Productive structure. JEL F14, L60, O10.

\title{
Introducción
}

Tras ocho años de fuerte crecimiento, la economía argentina comenzó a mostrar una marcada reducción de su dinámica productiva a partir del año 2011.

Esa reducción puede observarse, especialmente a partir del año 2014, en el sector industrial. En efecto, entre los años 2011-2016 el Valor Bruto de Producción (VBP) de dicho sector registró una caída del $14 \%$ en dólares constantes (frente a una merma del $6 \%$ al considerar al total de la economía). Esta dinámica está asociada al comportamiento registrado por el mercado interno y por el comercio exterior, ante el retorno de la restricción externa al crecimiento luego de registrar algunos años de superávit comercial. La reducción de dicho superávit por el lado de las exportaciones posee diversos fundamentos: caída de los precios de las commodities, contracción de la demanda externa, factores endógenos, etc. Esto se produce en un contexto de fuerte dependencia de la Argentina de las importaciones industriales técnicamente más complejas, cimentadas en la dependencia tecnológica de su entramado industrial; lo que genera una elevada correlación entre el crecimiento económico y el aumento de las importaciones de dichos bienes (Bekerman et al., 2015).

En relación a la caída de las exportaciones industriales se suele enfatizar al comportamiento del mercado de Brasil, dado el fuerte peso de este país como destino de los productos industriales argentinos, especialmente de aquellos que no pueden ser fácilmente colocados en terceros mercados (Bekerman; Dulcich, 2014). En estos sectores, una caída de la demanda de importación de esos productos por parte de Brasil puede generar un fuerte impacto sobre sus niveles de producción en la Argentina.

Esta realidad parece plantear una fuerte dependencia comercial de la actividad productiva de la Argentina con respecto a la situación macroeconómica de Brasil, en especial de sus niveles de actividad. Todo esto en un contexto de los menores niveles de crecimiento registrados por este país durante el período 2011-2016, lo que incluye un proceso de recesión durante los dos últimos años de ese período. En este punto cabe preguntarse ¿hasta qué punto los niveles de producción de la industria argentina dependen de la demanda de importaciones 
de Brasil? ¿Qué capacidad tuvieron los distintos sectores de sustituir dicho mercado por otros destinos de exportación y/o por las ventas al mercado interno?

Estas son las preguntas que intenta abordar este trabajo para el período 2011-2016. Por ende, su objetivo es detectar hasta qué punto la caída de las exportaciones industriales argentinas a Brasil afectaron el comportamiento del valor bruto de producción (VBP), tanto de la industria a nivel global como la de las distintas ramas que la integran en particular.

Para ello, en la sección 1 se presenta el marco teórico relevante para el objeto de estudio, mientras que en la sección 2 se realiza un breve abordaje macroeconómico para observar hasta qué punto se plantea una dependencia de las exportaciones argentinas en relación a la situación macroeconómica de Brasil a nivel general, considerando asimismo las perspectivas que presenta dicho país en materia de crecimiento. La sección 3 desarrolla un análisis de la dinámica industrial argentina y de las exportaciones a Brasil a nivel sectorial, buscando determinar el impacto de la caída en dichas exportaciones sobre el VBP de la industria y de cada sector en particular. Por último, en la sección 4 se presenta una síntesis y las conclusiones.

\section{Marco teórico}

Luego del elevado crecimiento de los países asiáticos de industrialización con orientación exportadora, la literatura relativa al crecimiento económico ahondó en las correlaciones y causalidades entre orientación exportadora y crecimiento del PBI. Balassa (1978) demostró para diversos países en un estadio intermedio de desarrollo que la orientación exportadora afecta positivamente el crecimiento económico. Feder (1982), nuevamente para una muestra de países semi-industrializados, demuestra que la relocalización de recursos hacia los sectores de mayor orientación exportadora genera un aumento de productividad agregada de la economía, ante la existencia de externalidades intersectoriales del proceso exportador. Marin (1992), para el caso de cuatro países desarrollados, demuestra que mayores exportaciones afectan positivamente la productividad; por lo que concluye que una mayor orientación exportadora favorece el crecimiento económico tanto en países en desarrollo (proceso abordado ampliamente por la literatura) como desarrollados.

Sin embargo, una mayor apertura económica, y especialmente una mayor orientación exportadora, expone a las economías en general y a los sectores exportadores en particular a las fluctuaciones del ciclo económico internacional; tópico específicamente relevante para nuestro objeto de estudio, que aborda el efecto de la caída de exportaciones a Brasil en la producción a nivel global y sectorial de la Argentina. Prasad (1999), para siete países desarrollados, destaca que los shocks macroeconómicos que afectan el nivel de actividad se transmiten asimismo hacia los saldos comerciales de dichos países. Por su parte, Calderón et al. (2003), para una muestra de 147 países entre 1960 y 1999, demuestran que una mayor integración comercial entre distintos países aumenta la correlación del ciclo económico entre 
los mismos; efecto que es más intenso-en el caso de socios entre los que predomina el comercio intra-industrial (y por ende que tienen características estructurales similares).

Bajo estos resultados, es importante destacar que la integración comercial regional, como la existente entre la Argentina y Brasil a través del Mercosur, aumentaría la correlación del ciclo económico entre ambos, especialmente considerando la existencia de un importante comercio intra-industrial (Durán Lima; Lo Turco, 2010). Sin embargo, más allá de esta convergencia, los objetivos de un proceso de integración son de índole estructural. Diversos autores atribuyen a la integración regional fuertes potencialidades para el desarrollo de ventajas comparativas dinámicas (Ffrench-Davis, 1991); no determinadas por la dotación de factores y el estado tecnológico de corto plazo de una economía. Dado que la existencia de fuertes brechas de productividad con los países desarrollados vuelve muy dificultosa la competencia de países en desarrollo en el mercado mundial (Chang, 2003), la integración económica ofrece cierta protección frente a la oferta extrarregional y permite fomentar el desarrollo tanto de la eficiencia estática como de la dinámica (Bekerman; Sirlin, 1996). En primer lugar, permite un avance en la determinación estática de especialización intrarregional, a partir de una localización más eficiente de los recursos dentro de la región, aprovechando la existencia del mercado ampliado. En ese sentido, las ganancias de escala y especialización de las unidades productivas, pueden permitir el desarrollo de fragmentos de las cadenas de valor en el interior de la región, y aumentos en los niveles de productividad ${ }^{1}$. Complementariamente, el proceso dinámico de aprendizaje, en términos de incorporación y desarrollo de nuevas técnicas, generan externalidades que se derraman hacia la totalidad de la estructura productiva regional, generando mejoras en los niveles de competitividad de la región con respecto a terceros países.

En este marco, y considerando específicamente a la Argentina y su especialización internacional fuertemente concentrada en pocos productos (Bekerman; Dulcich, 2013), la integración regional permite una diversificación exportadora hacia dicho mercado que es una condición necesaria (pero no suficiente) para desarrollar nuevas ventajas comparativas dinámicas con terceros mercados. Dicha diversificación exportadora posee ventajas por sí misma, como ayudar a reducir la volatilidad del ingreso de divisas por exportaciones y, por lo tanto, del crecimiento de la economía (Agosin, 2009). Esto es sobre todo relevante para los países en desarrollo, que suelen tener escaso acceso al mercado financiero internacional para cubrir déficits coyunturales de la cuenta corriente y que, por lo general, son muy dependientes de bienes de capital e insumos importados. Por otra parte, la diversificación exportadora implica una transformación productiva que permite que los agentes locales "descubran" las ventajas comparativas inexploradas de su economía, donde los pioneros exportadores les

(1) Al considerar la existencia de rendimientos crecientes a escala al interior de las firmas, Krugman (1979) remarca que el comercio internacional puede desarrollarse para aprovechar dichas economías de escala internas a la firma, en el marco de competencia imperfecta; a pesar de que los socios comerciales en cuestión posean similar dotación de recursos, tecnología y preferencias. Posteriormente, el autor especificó el modelo determinando que ante la existencia de costos de transporte, economías de escala, y heterogeneidad de preferencias entre países; el tamaño y composición del mercado doméstico van a incidir en la especialización internacional de las diversas economías, que van a tender a exportar los productos de fuerte participación en su mercado interno (Krugman, 1980). 
muestran el camino a los continuadores (Hausmann; Rodrik, 2003). En la medida en que los países presentan una canasta de exportaciones de alta calidad, basada en artículos más sofisticados, registran un crecimiento posterior más alto que los países que no lo hacen (Rodrik, 2005). En este contexto, es muy importante que el proceso de migración de productores hacia nuevos sectores no se vea bloqueado por excesivas barreras (patentes, elevadas escalas mínimas eficientes, entre otras). Estos procesos de diversificación productiva generan, además, una gama de externalidades (incremento de la productividad debido a la especialización productiva de los agentes, aumento de la calificación de la mano de obra, y otras) que repercuten positivamente en el crecimiento. Aquí aparece un rol importante del Estado "guiando al mercado" en el descubrimiento de estas nuevas capacidades (Wade, 1989).

Sin embargo, es importante remarcar que puede darse el caso de que no lleguen a cerrarse las brechas de productividad o calidad con los estándares de frontera internacional, determinando que las exportaciones se vuelvan posibles en el mercado regional, pero no así en terceros destinos. Estaríamos frente al caso de lo que denominamos bienes regionales que, al depender de la demanda del socio regional, pueden generar una situación de dependencia exportadora con respecto a las compras que realice dicho socio; situación que se aprecia en varios sectores argentinos con respecto al mercado de Brasil (Bekerman; Dulcich, 2014), como podremos observar en este trabajo. En otras palabras, puede hablarse de una situación que, en la medida en que no avanza hacia un proceso dinámico de aumento de la productividad y/o diferenciación de producto, plantea una situación de fragilidad o vulnerabilidad externa del país exportador. Por otro lado, si los procesos técnicos y de calidad de productos hacen posible su colocación sólo en el ámbito regional, esto puede estar fundamentado en que se generaron comportamientos de rent seeking en las unidades productivas, pero ahora desarrollados a escala regional. Aquí juega un rol esencial el diseño y la implementación de incentivos, tanto en el nivel nacional como regional, que, más allá de la competencia mercantil, estimulen los procesos de incorporación y desarrollo de técnicas productivas más eficientes, como lo demuestra la experiencia de los tigres asiáticos (Chang, 1993).

\section{Dependencia comercial y perspectivas macroeconómicas en Brasil}

En esta sección analizaremos, en primer lugar, la dependencia de las exportaciones argentinas con respecto a la situación macroeconómica de Brasil. Posteriormente, al identificar la relevancia de dicho mercado para las exportaciones argentinas a nivel general, analizaremos cuales son las perspectivas de la macroeconomía de Brasil.

\subsection{Trayectoria macroeconómica y competitividad internacional de la industria argentina}

En la última década y media, la interacción entre la macroeconomía y la inserción internacional de la industria argentina evidenció distintas etapas. Luego de la crisis económica que determinó el fin de la convertibilidad, el nuevo esquema macroeconómico implicó un tipo de cambio real depreciado y estable (Frenkel; Rapetti, 2007), que permitió una importante protección cambiaria. En este marco, la industria recuperó la utilización de la capacidad 
instalada vendiendo al mercado interno, e incluso algunas pudieron aumentar significativamente su orientación exportadora, como el sector petrolero, la minería y la industria automotriz (Bekerman et al., 2018).

Luego de la crisis internacional de 2009, los objetivos de tipo de cambio se sustituyeron por los de financiamiento del gasto, en el marco de la política anticíclica; por lo que el tipo de cambio real tendió a apreciarse. Este fenómeno, sumado a diversas políticas comerciales que buscaban contener las importaciones (controles en la demanda de divisas, licencias no automáticas, declaraciones juradas anticipadas de importaciones), generaron que la industria argentina se orientara hacia el mercado interno. Este fenómeno se dio, con mayor o menor intensidad, en todos los sectores industriales; a costa de la pérdida de orientación exportadora, configurando el "sesgo antiexportador" de las políticas comerciales mencionadas (Bekerman et al., 2018).

El cambio de gobierno hacia finales del año 2015 dio nacimiento a un nuevo esquema económico (Neffa, 2017), que se centró en desregular el mercado de cambios (lo que implicó una fuerte devaluación inicial), reducir la utilización de instrumentos de administración de comercio exterior; e implementar un esquema de objetivos de inflación que se centró en una tasa de interés muy superior a la inflación, afectando los volúmenes de inversión. En este contexto, una gran cantidad de sectores industriales, especialmente los de mayor densidad tecnológica (computadoras, maquinaria y equipos eléctricos, y la cadena automotriz), se vieron afectados por la competencia externa; mientras que las ramas tradicionales basadas en recursos naturales (alimentos y bebidas, minería) retomaron su orientación exportadora favorecidos por el nuevo esquema cambiario y la reducción de las retenciones a la exportación (Bekerman et al., 2018).

\subsection{Integración productiva y dependencia comercial de Argentina con Brasil}

A nivel general, cabe destacar que Brasil es, junto con China, uno de los principales destinos de las exportaciones argentinas: acapara alrededor del 15\% de las mismas para el año 2016 (Gráfico 1), pese a haber sufrido una reducción importante a partir del año 2014, momento en el que llegó a representar el 20\% de las exportaciones totales.

En términos de los fundamentos de dicha relación comercial, distintos estudios analizan el peso del tipo de cambio real bilateral y del crecimiento relativo de ambas economías como determinante de la evolución del comercio bilateral. Heymann y Navajas (1998) estiman para el período 1970-1997 que ambas variables son determinantes fundamentales del comercio bilateral, pero que la mayor intensidad se presenta en el nivel de actividad.

Para un período más reciente, Dicovskiy y Kiper (2009) corroboran la primacía del crecimiento por sobre el tipo de cambio real bilateral para explicar la evolución del comercio

entre ambos países. A nivel mesoeconómico, diversos autores afirman que esto se vincula con la existencia de un fuerte comercio intraindustrial (Durán Lima; Lo Turco, 2010). 
El impacto positivo de los procesos de crecimiento económico en Brasil sobre sus compras en la Argentina se refleja en el alto nivel de la elasticidad ingreso que presentan sus importaciones desde este país. Heymann y Navajas (1998) estimaron la elasticidad ingreso de corto plazo de las importaciones de Brasil desde la Argentina en 1,46 para el período 19701997; mientras que Dicovskiy y Kiper (2009) estimaron dicha elasticidad ingreso en 2,3 para el período 1994-2008. Bekerman y Dulcich (2014) también estimaron la elasticidad ingreso de las importaciones de Brasil desde la Argentina, pero de largo plazo, arrojando como resultado una elasticidad de 2,12 para el período 1980-2011. Considerando los principales destinos de exportación de la Argentina, se trata del país que presenta el mayor nivel de elasticidad-ingreso de sus importaciones provenientes desde dicho país².

En ese contexto, cabe resaltar que la importancia de Brasil como destino de las exportaciones argentinas se vuelve más significativa para el caso de los sectores industriales (Gráfico A.1 del Anexo): sin contar la cadena automotriz, Brasil acapara estructuralmente entre un $20 \%$ y un $25 \%$ de las exportaciones industriales argentinas; con una fuerte caída en 20152016, por debajo del 20\%. Sin embargo, para la cadena automotriz dicha participación ha crecido de manera significativa durante toda la década, hasta acaparar el $80 \%$ de las ventas externas del sector (ver más detalles en la sección 3); y luego caer asimismo en los últimos años, por debajo del $70 \%{ }^{3}$.

Esta importancia de Brasil como destino de las ventas externas ha generado que, además del mencionado caso del sector automotriz, distintos sectores industriales argentinos sean fuertemente dependientes del mercado de Brasil para colocar sus exportaciones (Bekerman; Dulcich, 2014). Entre ellos, podemos destacar a las maquinarias mecánicas (Harmonized System 2002 -HS02- cód. 84), las maquinarias y aparatos eléctricos (HS02 85), los productos plásticos (HS02 39) y los productos químicos (HS02 28 y 29).

Esta situación de dependencia del mercado brasileño por parte de la industria argentina se ha visto agravada ante la creciente expansión de las exportaciones chinas en dicho destino. De hecho, en la última década todos los sectores mencionados, excepto el automotriz, han sufrido la expansión de las exportaciones chinas, perdiendo participación en el mercado de importación de Brasil (Bekerman; Dulcich, 2017); e incluso algunos han visto reducidas sus

(2) Sólo en los casos de Brasil, EE.UU. y Chile, dentro de los cinco principales destinos de exportación de la Argentina, la relación de largo plazo entre importaciones desde la Argentina y el PBI de dichos países muestra una relación estadísticamente significativo (Bekerman; Dulcich, 2014). En los dos casos restantes (China y Países Bajos) las importaciones desde Argentina pueden responder a otros fundamentos principales, como importaciones de sectores específicos menos vinculados a la evolución del nivel de actividad general y/o con fuertes determinantes de orden de política económica, como es el caso de las exportaciones del complejo sojero a China (Bekerman; Dulcich; Moncaut, 2014).

(3) A pesar de esa elevada relevancia del mercado brasileño para las exportaciones argentinas, estas exportaciones ocupan un lugar menos preponderante dentro de las importaciones totales de Brasil (Gráfico A.1 del Anexo). Si bien ha ganado participación en las importaciones automotrices (rondando entre el 30\% y el 35\% de las mismas), la Argentina acapara en la actualidad apenas el 2\% de las importaciones industriales de Brasil (excluyendo la cadena automotriz), participación que ha caído tendencialmente en la última década, ya que a comienzos de los dos mil se encontraba en torno al $6 \%$ de dicho mercado de importación. 
exportaciones a Brasil en términos absolutos (sustancias químicas orgánicas -HS02 29- y maquinaria y equipo electrónico -HS02 85-). Más allá de los sectores mencionados, la expansión de las exportaciones chinas hizo perder participación en el mercado de Brasil a una gran cantidad de sectores industriales de la Argentina, e incluso algunos primarios (como las hortalizas -HS02 07-). La industria automotriz se presenta como una excepción al respecto, ya que cuenta con una elevada protección de frontera (arancel extrazona del 35\% para vehículos) y la industria automotriz china aún posee una orientación a su mercado interno muy elevada, y un bajo desempeño exportador (Dulcich et al., 2018).

\subsection{Perspectivas macroeconómicas en Brasil}

La economía brasileña mostró altas tasas de crecimiento durante los primeros años de la década de los dos mil (Gráfico 1); para sufrir, al igual que la Argentina, una retracción económica originada en la crisis de 2008-2009, y una desaceleración de su crecimiento desde el 2012, que se transformó en estancamiento (y una recesión para el caso de Brasil) en los últimos años. Sin embargo, las proyecciones hasta el año 2020 de las tasas de crecimiento de ambos países rondan entre el $2 \%$ y el $3 \%$ anual, levemente superiores para el caso de la Argentina.

Desde 1999, Brasil ha aplicado una política macroeconómica de Metas de Inflación, a partir de la utilización de la tasa de interés nominal (la tasa Selic, del Sistema Especial de Liquidação e Custodia del Banco Central del Brasil) como principal instrumento orientado a efectivizar los objetivos antiinflacionarios. A pesar de que se obtuvieron resultados exitosos en materia de reducción y estabilización de la inflación, algunos autores vinculan dichos resultados con un proceso de apreciación nominal sufrida por la moneda brasileña (BarbosaFilho, 2008; Bresser-Pereira, 2015).

La extensa etapa de apreciación del tipo de cambio nominal y real (ver Gráfico A.2 del Anexo) permitió un aumento significativo del salario real, lo que junto a diversas políticas socioeconómicas (como la transferencia de ingresos de la Bolsa Família), permitieron reducir significativamente los niveles de pobreza ${ }^{4}$ y ayudaron a dinamizar fuertemente el consumo interno. Pero ese consumo se derivó, en gran medida, hacia los bienes importados, en el marco de un proceso de desindustrialización fundamentado en una combinación de altos términos de intercambio de los productos primarios, apreciación cambiaria y elevadas tasas de interés real (Bresser-Pereira, 2015) $)^{5}$. El creciente déficit comercial financiado principalmente con ingreso neto de capital financiero externo (Gráfico A.2 del Anexo) generó este esquema que ha sido definido por Bresser Pereira (2010) como una "política de crecimiento con ahorro externo".

(4) Según la FAO (2016) la pobreza extrema se redujo de 7,6\% en 2004 al 2,8\% en 2014, lo que en términos absolutos implica que alrededor de 36 millones de personas salieran de esta situación.

(5) Complementariamente, el contexto de apreciación real y crisis económica internacional significó una oportunidad para las grandes empresas brasileñas para comprar activos externos y deslocalizar parte de sus componentes industriales (Actis, 2015), de manera de mitigar la pérdida de competitividad que originaba la apreciación real. 
El correlato distributivo del esquema fue un aumento del salario real superior al aumento de la productividad, lo que impactó negativamente en la tasa de inversión. La ausencia de cambio estructural, y las reducidas fuentes de innovación y avances tecnológicos en la economía brasilera generaron tensiones distributivas e inflacionarias que desembocaron en políticas macroeconómicas restrictivas y dieron lugar a dinámicas de crecimiento del tipo stop and go (Araujo; Gentil, 2015). El modelo de crecimiento no logró modernizar la estructura productiva de forma de acompañar los cambios del lado de la demanda, ni emplear la fuerza de trabajo en sectores de mayor productividad (Mello; Rossi, 2016).

Manzano y Salas (2016), por su parte, marcan la caída de la inversión especialmente luego de la crisis internacional de 2008. A diferencia de los primeros años de la década del 2000, cuando la demanda agregada estuvo fuertemente impulsada por una conjunción de la cuenta externa, el consumo y la inversión, a partir de 2009 el principal motor de la producción ha sido el consumo, aunque este factor también presenta una merma en relación a los años previos a la crisis.

Sin embargo, la mayor caída de la inversión privada se observa en los años 2014 y 2015, con caídas interanuales superiores al 10\% (Oreiro, 2017). La principal causa fue la caída en la tasa de ganancia producto del aumento del costo laboral y la apreciación cambiaria. El margen de ganancia incluso se tornó negativo en términos reales, y quedó muy por debajo de la tasa Selic.

El componente público de la inversión también cayó considerablemente a partir de 2011. El componente inercial y estructural de los gastos sociales dejó menos margen para que la política fiscal se canalizara a la inversión. Mientras la política fiscal entre 2005 y 2010 fue canalizada predominantemente hacia la inversión pública, entre 2011 y 2014 se concentró en subsidios y exenciones al sector privado, lo que en parte explica el fracaso en retomar el crecimiento (Rodrigo Octávio, 2016).

A pesar de la fuerte tendencia al crecimiento de las importaciones de Brasil a partir del año 2007, el volumen de las exportaciones argentinas al mundo (donde predominan Brasil y China como destinos de exportación) permaneció prácticamente inalterado hasta el año 2011, cuando comienzan a retraerse lentamente. A partir de 2014, la crisis brasilera generó una importante caída en las importaciones de bienes por parte de este país, impactando en el volumen de bienes adquiridos en la Argentina, lo que se vio acentuado por una sustitución de orígenes de importación realizada por Brasil, donde aumentó la participación de las importaciones originarias de China (Bekerman; Dulcich, 2017); una expresión específica de un fenómeno más general y de más largo plazo vinculado a profundas transformaciones en la división internacional del trabajo (Dulcich, 2015). Esto impactó negativamente en la participación de Brasil como destino de las exportaciones argentinas (Gráfico 1). 
Gráfico 1

Evolución de la participación de Brasil como destino de las exportaciones argentinas, y del PBI y volumen de comercio exterior de Argentina y Brasil

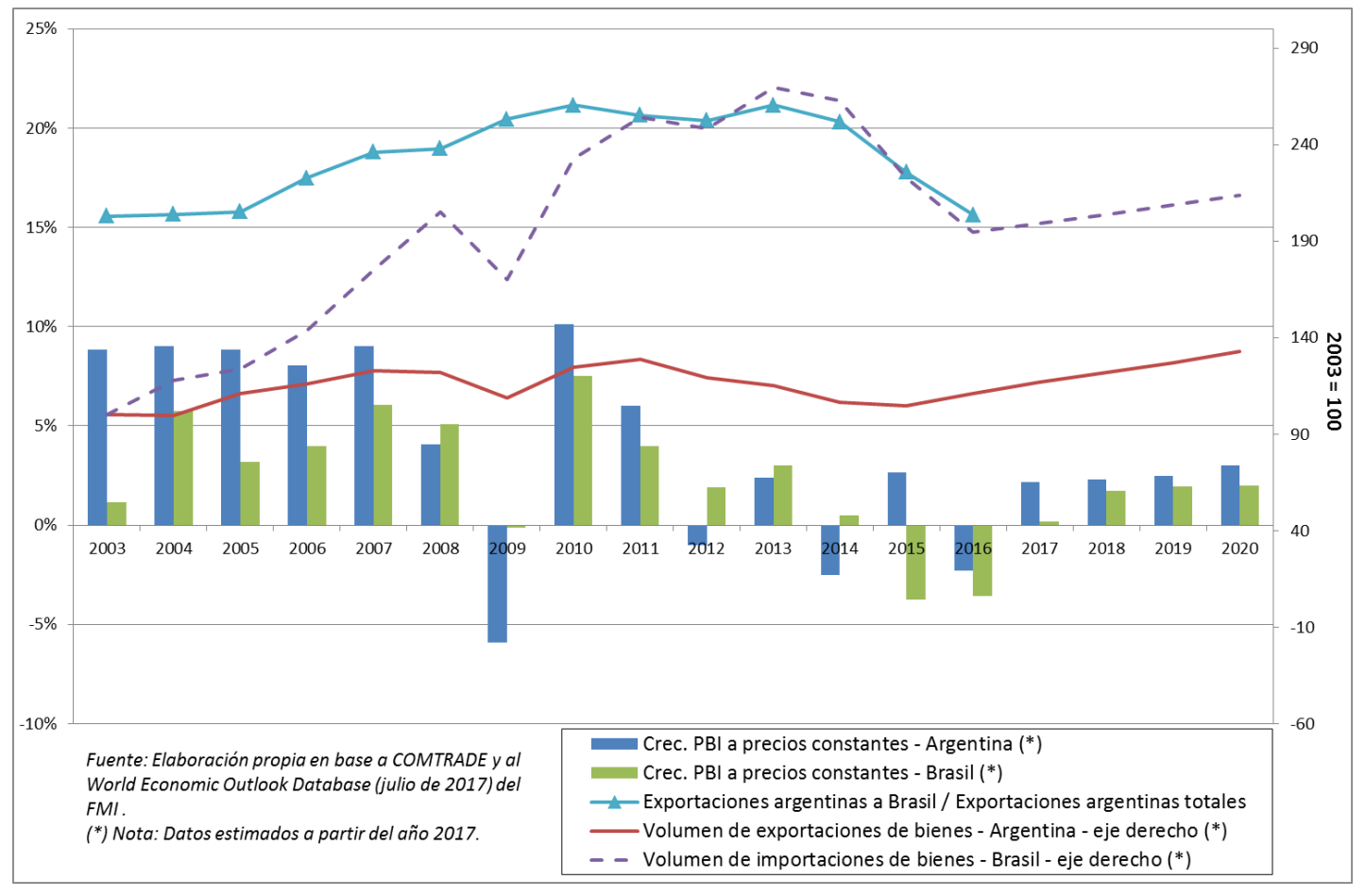

Con un nuevo gabinete económico, en el año 2015 se anunciaron importantes ajustes fiscales, así como un aumento de la tasa de interés (la Selic y la tasa del BNDES, entre otras) y del precio de los combustibles y la energía (Serrano; Summa, 2015), entre otras medidas. Según los autores, este ajuste fiscal se habría realizado con el objetivo de no perder el estatus de "grado de inversión" a nivel internacional, de manera de propiciar mayores ingresos de capital financiero internacional y generar un clima de confianza que motorice un crecimiento de la inversión.

Sin embargo, el plan de ajuste profundizó la caída en la inversión (Oreiro, 2017), la cual se desplomó un 30\% en términos reales entre comienzos de 2014 y comienzos de 2017, dando lugar a un deterioro en las expectativas de crecimiento de Brasil en el mediano plazo (FMI, 2017). Por otro lado, el PBI de Brasil muestra una caída de un -7,5\% acumulado entre 2015 y 2016, mermando la recaudación del tesoro y agudizando el déficit fiscal en relación al PBI, que creció de $-7 \%$ a -9,7\% entre 2014 y 2015, y fue de -7,5\% en 2016 (FMI, 2017).

Asimismo, la actual situación económica de Brasil no puede ser comprendida escindida de la crisis política que atraviesa el país. Luego del escándalo del caso "Lava Jato", se ha desencadenado una crisis de representación política que abre nuevos interrogantes sobre las perspectivas de crecimiento en el futuro cercano. 
Esta coyuntura económica impacta directamente sobre las exportaciones argentinas. Si bien durante la etapa de fuerte penetración importadora sufrida por Brasil fue posible un aumento de su participación como destino de las exportaciones de bienes argentinos, su impacto se vio limitado por el aumento de las ventas de otros proveedores, principalmente de China (Bekerman; Dulcich, 2017). Dicho desplazamiento de la Argentina por parte de terceros países se vio agravado ante la caída en las importaciones de Brasil a partir del proceso recesivo del año 2015. Es así que las exportaciones argentinas a Brasil cayeron un 35\% entre 2014 y 2016; con una reducción incluso superior (-46\%), para el caso de las manufacturas de origen industrial (Indec, 2016; Indec, 2017b). En 2017 se está evidenciando un pequeño repunte de las exportaciones a Brasil: en los primeros siete meses del año las mismas crecieron un 4,3\%, mientras que las exportaciones de manufacturas de origen industrial, por su parte, aumentaron un 3,4\% considerando el mismo periodo (Indec, 2017a). Si bien esto permite pensar que lo peor ha pasado, los niveles de las exportaciones argentinas a Brasil se encuentran muy por debajo de los niveles previos a la profunda recesión que sufriera la economía brasilera.

\section{El impacto sobre la producción}

La industria manufacturera argentina ha sufrido un proceso de deterioro a partir del 2011. En especial entre agosto de 2013 y marzo de 2015, el EMI evidenció 20 meses de caídas consecutivas en términos interanuales, y durante el resto del 2015 el crecimiento fue mínimo. Con el cambio de gobierno la situación empeoró nuevamente: entre febrero de 2016 y abril de 2017 el EMI registró 15 meses de caídas consecutivas a una tasa promedio de -4,3\% interanual, y aunque la tendencia se revirtió a partir de mayo de 2017, en julio de este año la producción industrial seguía siendo un 2,5\% inferior a la de julio de $2015^{6}$.

Es decir que la situación de la industria argentina, luego de tocar un techo en el año 2011, ha iniciado un sendero de estancamiento/recesión. Esto explica que las 22 ramas industriales consideradas hayan sufrido una caída en su valor bruto de producción (VBP) entre 2011 y 2016.

La merma en la producción puede ser explicada o bien por menores exportaciones (a Brasil o al resto del mundo) o bien por reducción del mercado interno. Si suponemos que la variación de existencias es nula, podemos determinar que toda la producción (en términos brutos, mediante el Valor Bruto de Producción, $V B P$ ) se vende en el mercado interno $(V)$ o se exporta $(X)$, desagregando los destinos según sean ventas a Brasil (supra índice $B$ ) o al resto del mundo (supra índice $R M$ ). De esta forma, para cada período $t$, tenemos que:

$$
V B P_{t}=X_{t}^{B}+X_{t}^{R M}+V_{t}
$$

Si diferenciamos dicha ecuación, tenemos que:

$$
\Delta V B P_{t}=\Delta X_{t}^{B}+\Delta X_{t}^{R M}+\Delta V_{t}
$$

( 6 ) Fuente: elaboración propia en base a INDEC. Disponible en http://www.indec.gob.ar/informacion-dearchivo.asp?solapa=7. Acceso: 1 Nov. 2017. 
Por lo que variaciones en el $V B P$ pueden ser explicadas por las variaciones de sus mercados de destino, suponiendo que no hay variaciones de stocks. En este sentido, es importante destacar que las ventas en el mercado interno $V$ (calculado mediante $V_{t}=V B P_{t}-$ $X_{t}$ ) son solo bienes de producción local, sin contemplar las importaciones. Dichas ventas pueden caer tanto por un menor dinamismo del mercado interno, como por la mayor entrada de importaciones, si estas desplazan producción nacional. A su vez, estas ventas pueden estar destinadas tanto a consumo como a inversión, según se trate de bienes de consumo o de capital.

La caída en el VBP entre 2011 y 2016 desagregada entre las exportaciones a Brasil, al resto del mundo y las ventas en el mercado interno se presenta en el Gráfico 2. Las caídas más marcadas, como es de esperar, se observan en las ramas que registran los mayores niveles de VBP. En efecto, en 2011 las ramas automotriz (34), metales comunes (27), alimentos y bebidas (15), productos de metal (28), maquinaria y equipo (29), y productos químicos (24) explicaban, en conjunto, las dos terceras partes de la producción industrial y su caída explica el 69\% de la merma total de dicha producción, para el período 2011-2016.

\section{Gráfico 2}

Variación lineal del VBP como resultado del comportamiento de las exportaciones a Brasil, de las exportaciones al resto del mundo (sin Brasil) y de las ventas en el mercado interno para el período 2011-2016.

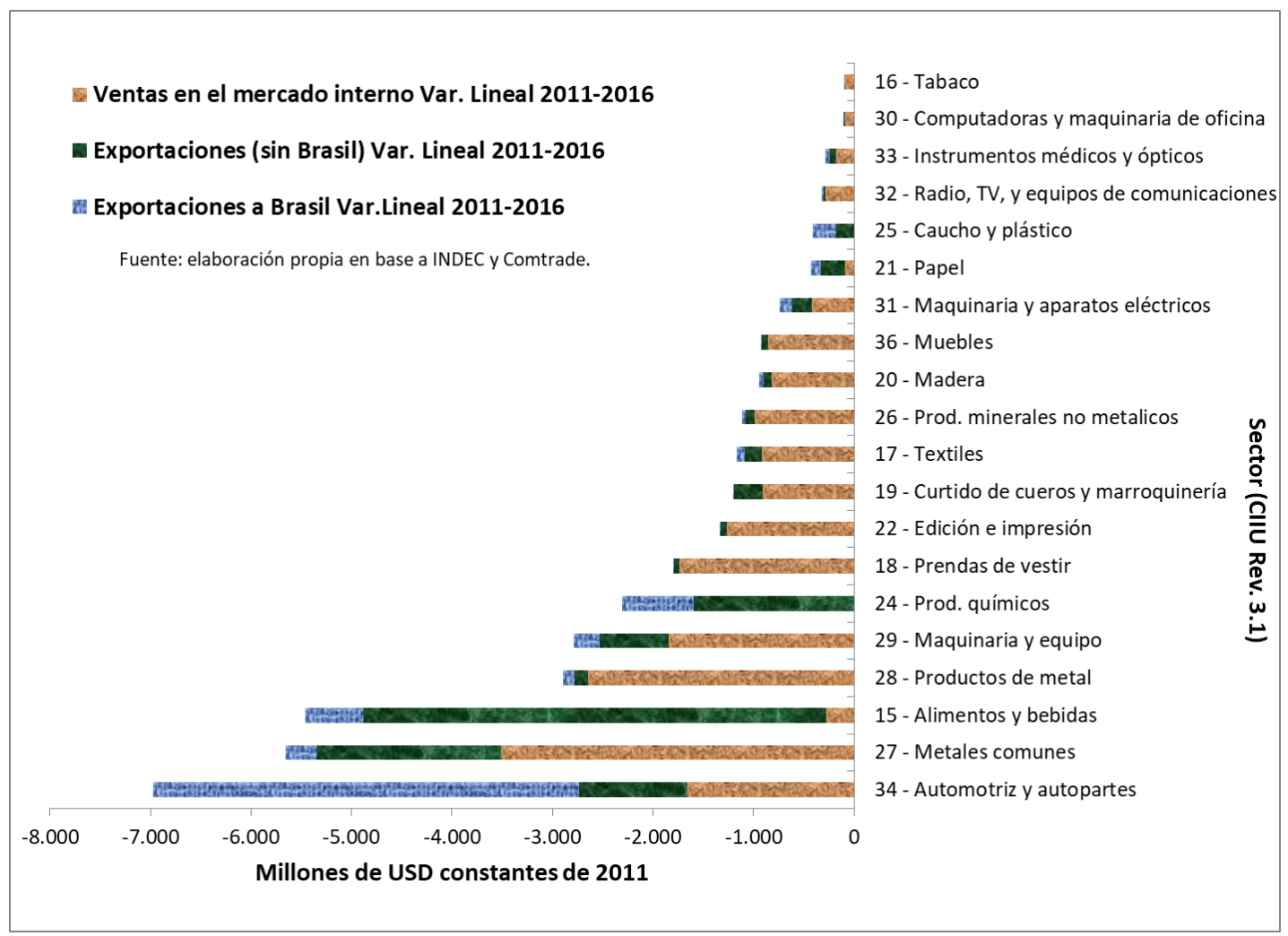


Pero los factores que explican la caída del VBP de cada una de esas ramas son heterogéneos, como puede observarse en el Gráfico 2. En el caso automotriz (34) la principal causa se vincula con las menores exportaciones a Brasil; en metales comunes (27), productos de metal (28), y maquinaria y equipo (29) el principal argumento se relaciona con las menores ventas en el mercado interno, mientras que en alimentos y bebidas (15) y productos químicos (24) el principal motivo de la caída en la producción son las menores exportaciones al resto del mundo, dado el alto coeficiente de exportación que presentan junto a un menor grado de regionalización.

En el resto de las ramas industriales, la caída en las ventas en el mercado interno es el principal factor que explica la reducción del VBP. Solo en las ramas de papel (21), y caucho y plástico (25) el efecto externo es mayor al interno. En el primer caso las exportaciones al resto del mundo (sin Brasil) son las que más cayeron, mientras que en caucho y plástico predomina el efecto de Brasil.

Al desagregar este comportamiento entre los subperíodos 2011-2013 y 2013-2016, de manera de captar posibles heterogeneidades vinculadas a la profundización de la crisis en Brasil en el segundo subperíodo (ver Gráfico 1), podemos destacar que entre 2013 y 2016 todas las ramas industriales argentinas presentan una caída en el VBP (Cuadro A.1 del Anexo). Sin embargo, esa caída se explica exclusivamente por las menores ventas en el mercado interno a partir de 2013. Las exportaciones a Brasil, en cambio, no presentan una dinámica muy diferente entre 2011-2013 y 2013-2016. Solo productos químicos (24) y la industria automotriz (34) presentan una caída de las exportaciones a Brasil sustancialmente mayor en el periodo 20132016 que en el periodo 2011-2013. En el sector automotriz la diferencia es especialmente notable. Mientras las exportaciones a Brasil crecieron 611 millones de dólares constantes entre 2011 y 2013, cayeron 4.842 millones entre 2013 y 2016.

La clasificación del Gráfico 2 nos permitió abordar las variaciones del VBP sectorial en términos absolutos. Sin embargo, como hemos mencionado, dichas variaciones reflejan en parte el peso relativo de los distintos sectores; pero no permiten ver la incidencia de dichas variaciones para el volumen de producción del propio sector, como porcentaje del mismo. Para abordar este tópico, en el Gráfico 3 podremos apreciar la variación del VBP sectorial en porcentajes en el eje horizontal; y cuánto de dicha variación (en términos absolutos), está explicada por las exportaciones a Brasil $\left(\frac{\Delta X_{t}^{B}}{\Delta V B P_{t}}\right)$, en el eje vertical. Ambas variables están calculadas para las variaciones registradas entre los años 2011 y 2016.

Sobre cada una de esas variables representadas en los ejes, armamos dos categorías. Consideramos que el impacto de las menores exportaciones a Brasil es "significativo" si explica más del 15\% de la caída en el VBP, y "poco significativo" si explica menos de dicho 
porcentaje. A su vez, consideremos que la caída en el VBP de producción es "considerable" si es superior al 6\%, y "menor" si es inferior a ese guarismo7.

Al cruzar esas dos variables con las dos clasificaciones cada una, obtenemos cuatro cuadrantes: el A incluye aquellas ramas en las que la caída de las exportaciones a Brasil es significativa y aparece asociada a una reducción considerable de la producción; el B está compuesto por aquellas ramas en las que el efecto Brasil es significativo pero donde se presenta una caída menor de la producción; el C representa las ramas en las que Brasil es poco significativo, a pesar de que la caída en la producción es considerable, y por último el cuadrante D comprende a las ramas en las que Brasil es poco significativo y que presentan una caída menor de la producción.

Gráfico 3

Variación porcentual del VBP, y ratio entre la variación lineal de las exportaciones a Brasil y la variación lineal del VBP para el período 2011-2016

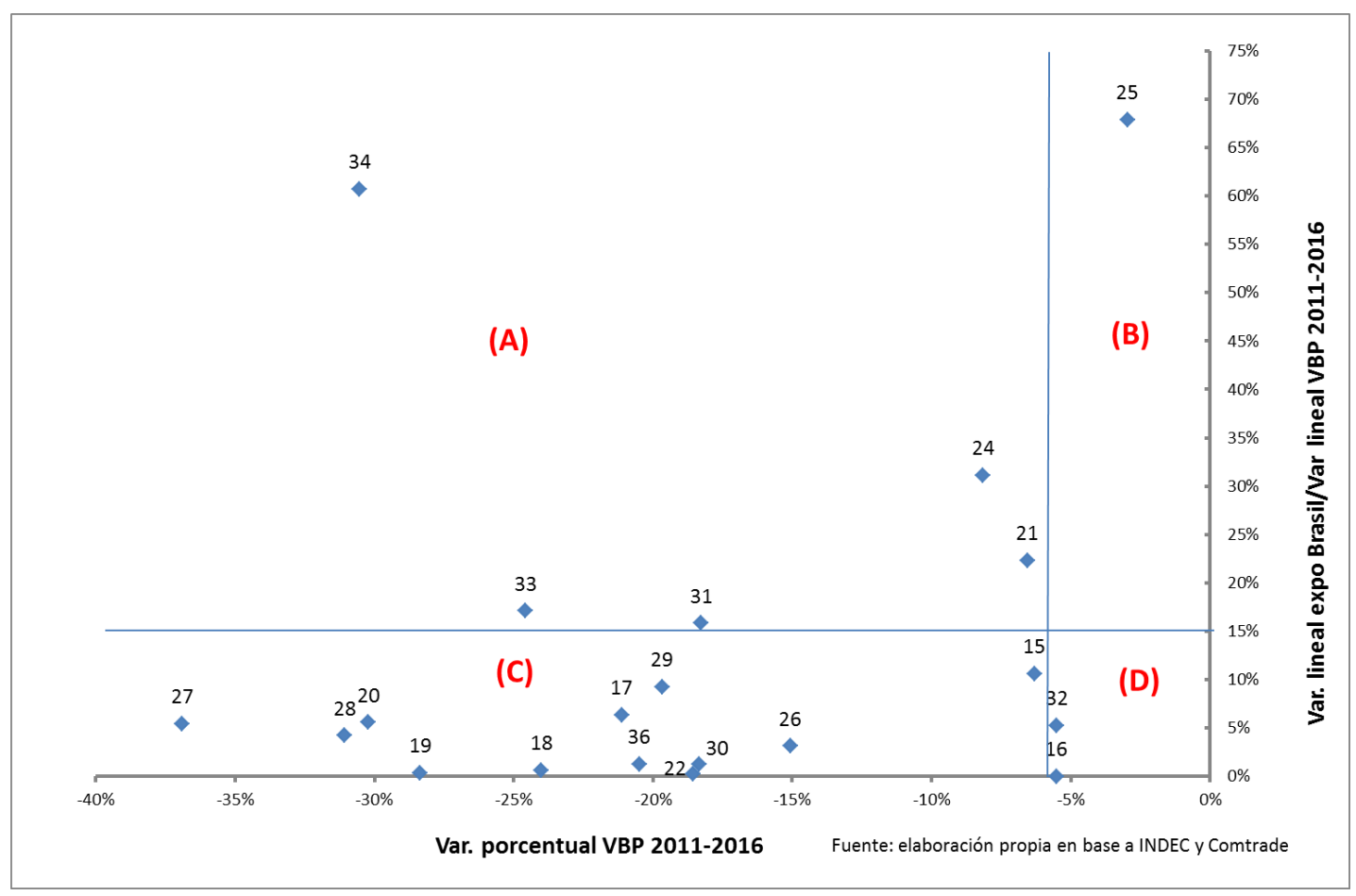

La descripción de las ramas que componen los cuatro cuadrantes, así como las magnitudes del impacto de las exportaciones a Brasil sobre el VBP de dichas ramas se presenta en el cuadro $\mathrm{N}^{\circ} 1$. Puede observarse, por un lado, que la disminución en las exportaciones a Brasil afecta casi exclusivamente al sector industrial, ya que éste genera alrededor del $80 \%$ de

(7) Este criterio surge de considerar la situación de la economía en su conjunto, donde la caída en el VBP fue del $6 \%$ entre 2011 y 2016, y el efecto de las menores exportaciones globales a Brasil explica el 15\% de dicha caída (ver Cuadro 1). 
las exportaciones totales al país vecino. Por otro lado, la merma en las exportaciones industriales a Brasil explica un $22 \%$ de la caída en la producción de dicho sector.

Cuadro 1

Exportaciones a Brasil, exportaciones al mundo y VBP de las ramas industriales para el período 2011-2016

\begin{tabular}{|c|c|c|c|c|c|c|c|c|c|c|c|c|c|c|c|}
\hline \multirow[b]{2}{*}{ Clasificación } & \multirow[b]{2}{*}{$\begin{array}{c}\text { ClaNAE } \\
2004-\text { CIIU } \\
3.1\end{array}$} & \multirow[b]{2}{*}{ Descripción } & \multicolumn{3}{|c|}{$\begin{array}{l}\text { Exportaciones a Brasil } \\
\text { (Mill. USS } \\
\text { constantes de 2011) }\end{array}$} & \multicolumn{4}{|c|}{$\begin{array}{c}\text { VBP } \\
\text { (Mill. USS } \\
\text { constantes de 2011) }\end{array}$} & \multicolumn{3}{|c|}{\begin{tabular}{|c} 
Exportaciones a Brasil / \\
VBP \\
(Mill. U\$S \\
constantes de 2011)
\end{tabular}} & \multicolumn{3}{|c|}{$\begin{array}{l}\text { Exportaciones a Brasil / } \\
\text { Exportaciones al mundo (\%) }\end{array}$} \\
\hline & & & $\begin{array}{l}2011 \\
\text { (a) }\end{array}$ & $\begin{array}{l}2016 \\
\text { (b) }\end{array}$ & $\begin{array}{l}\text { Var. lineal } \\
2011-2016 \\
(\mathrm{c}=\mathrm{b}-\mathrm{a})\end{array}$ & $\begin{array}{c}2011 \\
\text { (d) }\end{array}$ & $\begin{array}{c}2016 \\
(\mathrm{e})\end{array}$ & $\begin{array}{l}\text { Var. lineal } \\
2011-2016 \\
(\mathrm{f}=\mathrm{e}-\mathrm{d})\end{array}$ & $\begin{array}{c}\text { Var. } \\
\text { Porcentual } \\
\text { 2011-2016 }\end{array}$ & $\begin{array}{l}2011 \\
(g= \\
a / d)\end{array}$ & $\begin{array}{l}2016 \\
(\mathrm{~h}= \\
\mathrm{b} / \mathrm{e})\end{array}$ & $\begin{array}{c}\text { Var. Lineal } \\
\text { Expo Brasil/ } \\
\text { Var. Lineal } \\
\text { VBP } \\
2011-2016 \\
(\mathbf{i}=\mathbf{c} / \mathrm{f})\end{array}$ & $\begin{array}{c}2011 \\
(\mathrm{j})\end{array}$ & $\begin{array}{c}2016 \\
(\mathrm{k})\end{array}$ & $\begin{array}{c}\text { Variación } \\
\text { lineal } \\
2011-2016 \\
(\mathrm{k}-\mathrm{j})\end{array}$ \\
\hline \multirow{5}{*}{\begin{tabular}{|c|} 
A \\
Brasil \\
significativo y \\
caida \\
considerable del \\
VBP
\end{tabular}} & 34 & $\begin{array}{l}\begin{array}{l}\text { Fabricación de vehículos } \\
\text { automotores, remolques y } \\
\text { semirremolques }\end{array} \\
\end{array}$ & 7.524 & 3.292 & -4.232 & 22.828 & 15.858 & -6.970 & $-31 \%$ & $33 \%$ & $21 \%$ & $61 \%$ & $74 \%$ & $67 \%$ & $-7 \%$ \\
\hline & 24 & $\begin{array}{l}\text { Fabricación de sustancias y } \\
\text { productos químicos }\end{array}$ & 1.832 & 1.127 & -705 & 27.795 & 25.531 & -2.264 & $-8 \%$ & $7 \%$ & $4 \%$ & $31 \%$ & $25 \%$ & $22 \%$ & $-3 \%$ \\
\hline & 21 & $\begin{array}{l}\begin{array}{l}\text { Fabricación de papel y de } \\
\text { productos de papel }\end{array} \\
\end{array}$ & 202 & 107 & -95 & 6.514 & 6.087 & -428 & $-7 \%$ & $3 \%$ & $2 \%$ & $22 \%$ & $31 \%$ & $34 \%$ & $3 \%$ \\
\hline & 33 & $\begin{array}{l}\text { Fabricación de instrumentos } \\
\text { médicos, ópticos y de precisión; } \\
\text { fabricación de relojes }\end{array}$ & 76 & 27 & -49 & 1.170 & 883 & -288 & $-25 \%$ & $6 \%$ & $3 \%$ & $17 \%$ & $34 \%$ & $23 \%$ & $-11 \%$ \\
\hline & 31 & $\begin{array}{l}\text { Fabricación de maquinaria y } \\
\text { aparatos eléctricos n.c.p. }\end{array}$ & 144 & 28 & -117 & 4.033 & 3.297 & -737 & $-18 \%$ & $4 \%$ & $1 \%$ & $16 \%$ & $32 \%$ & $21 \%$ & $-11 \%$ \\
\hline \begin{tabular}{|c|} 
B \\
Brasil \\
significativo y \\
caida menor del \\
VBP
\end{tabular} & 25 & $\begin{array}{l}\text { Fabricación de productos de } \\
\text { caucho y plástico }\end{array}$ & 449 & 223 & -226 & 11.236 & 10.903 & -334 & $-3 \%$ & $4 \%$ & $2 \%$ & $68 \%$ & $48 \%$ & $42 \%$ & $-6 \%$ \\
\hline \multirow{12}{*}{\begin{tabular}{|c|} 
C \\
Brasil poco \\
significativo y \\
caida \\
considerable del \\
VBP
\end{tabular}} & 15 & $\begin{array}{l}\text { Elaboración de productos } \\
\text { alimenticios y bebidas }\end{array}$ & 1.749 & 1.171 & -579 & 86.662 & 81.202 & -5.460 & $-6 \%$ & $2 \%$ & $1 \%$ & $11 \%$ & $7 \%$ & $6 \%$ & $-1 \%$ \\
\hline & 29 & $\begin{array}{l}\text { Fabricación de maquinaria y equipo } \\
\text { n.c.p. }\end{array}$ & 449 & 190 & -259 & 14.185 & 11.395 & -2.790 & $-20 \%$ & $3 \%$ & $2 \%$ & $9 \%$ & $27 \%$ & $27 \%$ & $0 \%$ \\
\hline & 17 & Fabricación de productos textiles & 110 & 36 & -74 & 5.513 & \begin{tabular}{|l|l|}
4.348 \\
\end{tabular} & -1.164 & $-21 \%$ & $2 \%$ & $1 \%$ & $6 \%$ & $24 \%$ & $16 \%$ & $-7 \%$ \\
\hline & 20 & \begin{tabular}{|l|}
$\begin{array}{l}\text { Producción de madera y } \\
\text { fabricación de productos de madera } \\
\text { y corcho, excepto muebles; } \\
\text { fabricación de artículob de paja y } \\
\text { de materiales trenzables }\end{array}$ \\
\end{tabular} & 56 & 3 & -53 & 3.143 & 2.194 & -950 & $-30 \%$ & $2 \%$ & $0 \%$ & $6 \%$ & $26 \%$ & $3 \%$ & $-23 \%$ \\
\hline & 27 & Fabricación de metales comunes & 470 & 162 & -308 & 15.332 & \begin{tabular}{|l|l|}
9.675 \\
\end{tabular} & -5.657 & $-37 \%$ & $3 \%$ & $2 \%$ & $5 \%$ & $9 \%$ & $5 \%$ & $-4 \%$ \\
\hline & 28 & $\begin{array}{l}\text { Fabricación de productos } \\
\text { elaborados de metal, excepto } \\
\text { maquinaria y equipo }\end{array}$ & 189 & 67 & -122 & 9.329 & 6.431 & -2.898 & $-31 \%$ & $2 \%$ & $1 \%$ & $4 \%$ & $41 \%$ & $32 \%$ & $-9 \%$ \\
\hline & 26 & $\begin{array}{l}\text { Fabricación de productos minerales } \\
\text { no metálicos }\end{array}$ & 46 & 11 & -35 & 7.406 & 6.290 & -1.116 & $-15 \%$ & $1 \%$ & $0 \%$ & $3 \%$ & $17 \%$ & $8 \%$ & $-9 \%$ \\
\hline & 30 & \begin{tabular}{|l|}
$\begin{array}{l}\text { Fabricación de maquinaria de } \\
\text { oficina, contabilidad e informática }\end{array}$ \\
\end{tabular} & 2 & 0 & -1 & 556 & 454 & -102 & $-18 \%$ & $0 \%$ & $0 \%$ & $1 \%$ & $11 \%$ & $5 \%$ & $-5 \%$ \\
\hline & 36 & $\begin{array}{l}\text { Fabricación de muebles y } \\
\text { colchones; industrias } \\
\text { manufactureras n.c.p. }\end{array}$ & 16 & 4 & -12 & 4.545 & 3.614 & -932 & $-20 \%$ & $0 \%$ & $0 \%$ & $1 \%$ & $13 \%$ & $9 \%$ & $-4 \%$ \\
\hline & 18 & $\begin{array}{l}\begin{array}{l}\text { Fabricación de prendas de vestir; } \\
\text { terminación y teñido de pieles }\end{array} \\
\end{array}$ & 19 & 8 & -12 & 7.508 & 5.706 & -1.802 & $-24 \%$ & $0 \%$ & $0 \%$ & $1 \%$ & $16 \%$ & $15 \%$ & $-1 \%$ \\
\hline & 19 & $\begin{array}{l}\text { Curtido y terminación de cueros; } \\
\text { fabricación de artículos de } \\
\text { marroquinería, talabartería y } \\
\text { calzado y de sus partes }\end{array}$ & 8 & 3 & -5 & 4.243 & 3.040 & -1.203 & $-28 \%$ & $0 \%$ & $0 \%$ & $0 \%$ & $1 \%$ & $0 \%$ & $0 \%$ \\
\hline & 22 & $\begin{array}{l}\begin{array}{l}\text { Edición e impresión; reproducción } \\
\text { de grabaciones }\end{array} \\
\end{array}$ & 6 & 2 & -4 & 7.187 & 5.854 & -1.333 & $-19 \%$ & $0 \%$ & $0 \%$ & $0 \%$ & $5 \%$ & $5 \%$ & $0 \%$ \\
\hline \multirow{2}{*}{\begin{tabular}{|c} 
D \\
Brasil poco \\
significativo y \\
caida menor del \\
VBP
\end{tabular}} & 32 & $\begin{array}{l}\text { Fabricación de equipos y aparatos } \\
\text { de radio, televisión y } \\
\text { comunicaciones }\end{array}$ & 31 & 14 & -17 & \begin{tabular}{|l|} 
\\
\end{tabular} & 5.476 & -319 & $-6 \%$ & $1 \%$ & $0 \%$ & $5 \%$ & $51 \%$ & $49 \%$ & $-3 \%$ \\
\hline & 16 & $\begin{array}{l}\text { Elaboración de productos de } \\
\text { tabaco }\end{array}$ & 0 & 0 & 0 & 1.662 & 1.571 & -92 & $-6 \%$ & $0 \%$ & $0 \%$ & $0 \%$ & $0 \%$ & $0 \%$ & $0 \%$ \\
\hline Caso particular & 23 & $\begin{array}{l}\begin{array}{l}\text { Fabricación de coque, productos } \\
\text { de la refinación del petróleo y } \\
\text { combustible nuclear }\end{array} \\
\end{array}$ & 1.439 & 201 & -1.238 & 16.962 & 16.751 & -211 & $-1 \%$ & $8 \%$ & $1 \%$ & $586 \%$ & $57 \%$ & $35 \%$ & $-22 \%$ \\
\hline \multirow{2}{*}{\multicolumn{3}{|c|}{$\begin{array}{l}\text { STRIA MANUFACTURE } \\
\text { TOTAL }\end{array}$}} & \begin{tabular}{|l|}
14.903 \\
17.17
\end{tabular} & 6.678 & -8.226 & 266.194 & \begin{tabular}{|l|}
228.398 \\
0.49
\end{tabular} & $\begin{array}{l}-37.796 \\
\end{array}$ & $-14 \%$ & $6 \%$ & $3 \%$ & $22 \%$ & $25 \%$ & $18 \%$ & $-8 \%$ \\
\hline & & & \begin{tabular}{|l|l|}
17.317 \\
\end{tabular} & 9.028 & -8.289 & 870.938 & 814.945 & -55.993 & $-6 \%$ & $2 \%$ & $1 \%$ & $15 \%$ & $21 \%$ & $16 \%$ & $-5 \%$ \\
\hline
\end{tabular}


En las siguientes subsecciones se analizan los sectores involucrados en cada una de las categorías en particular.

\subsection{Ramas industriales en las que Brasil es significativo y que presentan una caída considerable del VBP (Cuadrante A)}

Las ramas industriales en las que la caída en las exportaciones a Brasil impactó de manera significativa sobre la producción, y a su vez la disminución del VBP entre 2011 y 2016 fue considerable (mayor al 6\%) son: automotriz (34), sustancias y productos químicos (24), papel (21), instrumentos médicos, ópticos y de precisión (33) y maquinaria y aparatos eléctricos (31).

El caso de la fabricación de vehículos automotores, remolques y semirremolques (34) es emblemático. Esta rama se vio fuertemente perjudicada por la caída en las exportaciones a Brasil, pues buena parte de su producción se exporta a ese país, cuya demanda es especialmente sensible con respecto al nivel de actividad. Así, las exportaciones argentinas cayeron en más de 4.000 millones de dólares entre 2011 y 2016, explicando el 61\% de la caída en el VBP del sector. Al interior de la rama los vehículos más afectados fueron los de cilindrada superior a $1.500 \mathrm{~cm}^{3}$ pero inferior o igual a $3.000 \mathrm{~cm}^{3}$, cuyas exportaciones cayeron en más de 1.000 millones de dólares, a una tasa promedio anual de $-25 \%$. Los vehículos de cilindrada inferior a $1.000 \mathrm{~cm}^{3}$ también sufrieron el impacto recesivo de la economía brasilera en las exportaciones, las cuales cayeron en más de 700 millones de dólares a un promedio anual del -26\% (Cuadro A.2 del Anexo $)^{8}$. Por otro lado, este sector sufrió también la reducción de las ventas en el mercado interno, en parte por la caída en las ventas en general, pero también por las mayores importaciones, las cuales crecieron un 18,3\% entre 2015 y 2016 (Indec, 2017b).

La fabricación de sustancias y productos químicos (24) también sufrió el impacto de la caída de exportaciones a Brasil de manera significativa. Si bien el peso de las exportaciones al país vecino en relación al VBP es mucho menor que en la rama automotriz, la caída en las exportaciones explica el 31\% de la disminución en el VBP. El 69\% restante es explicado por la caída en las exportaciones al resto del mundo, ya que las ventas al mercado interno no se redujeron. Las exportaciones a Brasil cayeron principalmente por lo acaecido con los desodorantes corporales y antitranspirantes (Cuadro A.2 del Anexo). El resto de los productos no se vieron significativamente afectados.

En el caso de la fabricación de papel y productos de papel (21), las exportaciones cayeron en 95 millones de dólares, lo que explica un 22\% de la caída en el VBP de la rama, en consonancia con el promedio de la industria. El resto de la disminución en el VBP se explica principalmente por las menores exportaciones al resto del mundo, pues las ventas internas no

(8) En los Cuadros A.2, A.3, A.4, y A.5 del Anexo se presentan los principales subsectores (a seis dígitos de la clasificación Harmonized System 2002 - HSO2-) pertenecientes a los sectores analizados (categorizados a dos dígitos de la Clasificación Industrial Internacional Uniforme - CIIU-, revisión 3). Los subsectores seleccionados son los tres subsectores de mayor valor exportado a Brasil para el período 2011-2016 en cada sector clasificado por la CIIU. 
La caída de las exportaciones industriales a Brasil, ¿cuánto afectó a la producción argentina?

se vieron especialmente afectadas. Por esta razón la variación porcentual de la producción entre 2011 y 2016 fue de $-7 \%$, por debajo del promedio de la industria. Al desagregar las exportaciones observamos que el producto más afectado fue la pasta química de madera, que explica más de la mitad de las exportaciones de la rama (Cuadro A.2 del Anexo).

La merma en las exportaciones a Brasil de instrumentos médicos, ópticos y de precisión (33), por su parte, explica el 17\% de la caída en la producción de la rama. No se trata de una rama con una elevada orientación exportadora, por lo que el principal motivo de la caída en la producción fue el menor dinamismo del mercado interno. Particularmente los instrumentos y aparatos automáticos explican casi dos terceras partes de la caída en las exportaciones, con una variación promedio anual del -34\% entre 2011 y 2016 (Cuadro A.2 del Anexo).

Asimismo las exportaciones a Brasil de maquinaria y aparatos eléctricos (31) cayeron a una tasa promedio anual del $-28 \%$, hecho que explica un $16 \%$ de la merma en el VBP de la rama. Si bien el porcentaje de la producción exportado a Brasil ya era bajo en 2011, la caída en las exportaciones llevó ese valor a sólo 28 millones de dólares, lo que representa un 1\% del VBP de la rama.

\subsection{Ramas industriales en las que Brasil es significativo y presentan una caída menor del VBP (cuadrante B)}

Solo una rama sufrió de manera significativa la caída en las exportaciones a Brasil y tuvo una caída menor (inferior al 6\%) de su producción. Se trata de la fabricación de productos de caucho y plástico (25). En el resto de las ramas en las que Brasil fue "significativo" la merma en el VBP fue considerable.

La fabricación de productos de caucho y plástico (25) ha sido fuertemente afectada por la recesión brasilera y las consecuentes menores exportaciones a este destino, ya que este factor explica el 68\% de la caída en el VBP de la rama. Sin embargo, la reducción del VBP sectorial en dicho período fue de tan solo el 3\% entre 2011 y 2016, por lo que se ubica en el cuadrante B del Gráfico 2. Al desagregar, vemos que la fabricación de neumáticos explica la mayor caída en las exportaciones, en términos absolutos (Cuadro A.3 del Anexo); lo que demuestra la elevada incidencia de la cadena automotriz en el comercio bilateral entre Argentina y Brasil.

\subsection{Ramas industriales en las que Brasil es poco significativo y presentan una caída considerable del VBP (cuadrante $\mathrm{C}$ )}

Las ramas en las que el impacto de la recesión brasilera es poco significativo para explicar la caída en el VBP y que a su vez han sufrido una merma considerable en su producción son, en general, aquellas en las que el peso de las exportaciones al país vecino en relación al total producido es pequeño. Se trata de: alimentos y bebidas (15), maquinaria y equipo (29), textil (17), madera (20), metales comunes (27), productos elaborados de metal (28), productos minerales no metálicos (26), maquinaria de oficina (30), muebles y colchones (36), prendas de 
vestir (18), curtido y terminación de cueros (19) y edición e impresión (22). En todas ellas el porcentaje del VBP exportado a Brasil representaba entre el 0\% y el 3\% en 2011.

La rama de alimentos y bebidas (15) es la de mayor producción al interior de la industria manufacturera. Por esta razón, pese a ser la tercera en orden de reducción de la producción en términos absolutos, su caída porcentual entre 2011 y 2016 (-6\%) se encuentra por debajo del promedio industrial (-14\%). En este caso la caída en las exportaciones a Brasil representa un $11 \%$ de la reducción en el VBP y se explica principalmente por el comportamiento de la harina de trigo (ver Cuadro A.4 del Anexo). Con todo, el efecto se ve atenuado por el hecho de que Brasil representa solo el $6 \%$ de las exportaciones totales, y el $1 \%$ de la producción total de la rama. En este caso la caída de las exportaciones hacia otros destinos (especialmente China) es el principal factor para explicar la caída en la producción.

En el caso de maquinaria y equipo (29) las exportaciones a Brasil cayeron a una tasa promedio anual de $-16 \%$ entre 2011 y 2016 , en consonancia con la caída de las exportaciones al resto del mundo. Por eso esta rama es la única (entre las ramas que sufrieron el impacto de la recesión brasilera) en la que el peso de las exportaciones a Brasil en relación a las exportaciones totales no cayó (siguen representando el $27 \%$ de las exportaciones totales). Aun así, la reducción en las exportaciones al país vecino explica un 9\% de la disminución en el VBP de la rama. El principal factor en este caso es el achicamiento de las ventas al mercado interno.

Las exportaciones de productos textiles (17) a Brasil, por su parte, disminuyeron a una tasa promedio anual del 20\%, pero sólo explican un 6\% de la caída en el VBP de la rama, dado el escaso peso de sus exportaciones a Brasil (2\% de la producción sectorial en el año 2011). Esta rama se caracteriza por destinar sus ventas principalmente al mercado interno, pues es muy poco competitivo a nivel internacional. Pero incluso en el mercado interno ha perdido terreno, en parte ante los cambios acaecidos en la administración del comercio exterior desde el cambio de gobierno. Concretamente a partir de junio de 2016, finalizó la utilización de las DJAI y las importaciones textiles crecieron un 6,7\% en el año 2016 (en cantidades). Del total de dichas importaciones, el 77\% está desplazando producción nacional (ProTejer, 2017)

El caso de la producción de madera y sus productos (20) es similar, aunque la caída de las exportaciones a Brasil ha sido mucho más pronunciada en esta rama. Dichas exportaciones pasaron de 56 millones de dólares en 2011 a tan solo 3 millones en 2016, lo que arroja una variación promedio anual del $-46 \%$. De ese total, 50 millones de dólares corresponden a la caída de los tableros de fibra (Cuadro A.4 del Anexo). En consecuencia, la participación de Brasil como destino de exportación pasó del $26 \%$ al 3\%, y generó un $6 \%$ de caída en la producción de la rama.

La fabricación de metales comunes (27) también cayó de manera pronunciada entre 2011 y 2016. Después de vehículos automotores, es la rama que más redujo su tamaño en el periodo analizado. Sin embargo, en este caso el efecto de Brasil no es el principal factor explicativo de su caída. Si bien las exportaciones a este país se redujeron en más de 300 millones, a una tasa promedio anual del -19\%, esta dinámica solo explica el 5\% de la reducción 
La caída de las exportaciones industriales a Brasil, ¿cuánto afectó a la producción argentina?

en el VBP, mientras que las menores exportaciones a otros destinos representaron un $33 \%$ y la caída de las ventas en el mercado interno un $62 \%$. El producto más perjudicado al interior de esta rama en términos de sus exportaciones a Brasil fue aluminio sin alear, cuyas exportaciones cayeron a una tasa promedio anual del $-22 \%$, por encima del promedio del sector (Cuadro A.4 del Anexo).

En la rama de productos elaborados con metal (28) las exportaciones a Brasil cayeron en más de 100 millones de dólares entre 2011 y 2016. Sin embargo, dado que la disminución en el VBP fue de casi 3.000 millones en el mismo periodo, la merma en las exportaciones al país vecino apenas representan un $4 \%$ de la caída en el VBP de la rama. Nuevamente, resalta el mercado interno como la principal causa de la disminución en la producción.

Por su parte, en la rama de productos minerales no metálicos (26) el impacto de la recesión brasilera y las consecuentes menores ventas a este destino representa el 3\% de la caída en la producción. Lo pequeño del guarismo se explica fundamentalmente por el hecho de que ya en 2011 solo se exportaba a Brasil el 1\% del VBP. Por ende, pese a que las exportaciones a este destino cayeron a una tasa anual promedio del $-25 \%$, el efecto de la recesión de Brasil en la producción de la rama es marginal. Tampoco es significativa la caída en las exportaciones al resto del mundo, por lo que prácticamente la totalidad de la reducción en la producción se debe a las menores ventas en el mercado interno.

Dentro del cuadrante $\mathrm{C}$ también se encuentran las ramas de maquinaria de oficina (30), muebles y colchones (36), prendas de vestir (18), curtido y terminación de cueros (19) y edición e impresión (22). En todos estos casos el peso de las exportaciones a Brasil sobre el VBP es inferior al 1\%. Por esta razón, si bien dichas exportaciones se contrajeron en el período 2011 2016, el efecto sobre la caída en la producción es ínfimo. El principal factor para explicar la mengua del VBP fue, entonces, el desplome de las ventas al mercado interno. En el caso de maquinaria de oficina el descenso en el VBP (en términos absolutos) fue pequeño pues es una rama que ya de por si tiene poco peso en el entramado industrial argentino. En muebles, edición e impresión, curtidos de cuero y marroquinería, y prendas de vestir, en cambio, la caída en el VBP fue más considerable. Las últimas dos ramas, al igual que la textil, se vieron especialmente afectadas por las mayores importaciones, que desplazaron a la producción nacional. En el caso del cuero, éstas crecieron un 7,1\% entre 2015 y 2016, mientras que para ciertas prendas de vestir, como calzados, las mismas crecieron hasta un $30 \%$, en igual periodo (Indec, 2017b).

\subsection{Ramas industriales en las que Brasil es poco significativo y presentan una caída menor del VBP (cuadrante D), y un caso particular}

Las ramas en las que Brasil es poco significativo y la caída en la producción es menor son dos: equipos y aparatos de radio, televisión y comunicaciones (32) y tabaco (16).

Las exportaciones de equipos y aparatos de radio, televisión y comunicaciones (32) tienen un peso mínimo en relación al VBP de la rama. Por eso, pese a que las exportaciones a 
Brasil cayeron a una tasa promedio anual del 15\%, dicha caída representa solo un 5\% de la reducción de la producción de la rama. Dado el bajo coeficiente de exportación, prácticamente toda la caída en el VBP se explica por las menores ventas en el mercado interno.

En el caso del tabaco (16) la importancia de Brasil como destino de la producción argentina es todavía menor. De hecho, las exportaciones a este destino son prácticamente inexistentes, y por lo tanto no resulta un factor significativo para explicar la caída en la producción de la rama. Además dicha merma fue menor, al situarse justo por debajo del nivel de corte $(6 \%)$. En términos absolutos la magnitud de la caída también es chica porque el sector es uno de los de menor peso relativo en el entramado industrial.

Por último, la situación de la rama de refinación de petróleo (23) es particular, pues es la única en la cual la caída en el VBP es menor a la caída de las exportaciones a Brasil. Si bien éstas cayeron en 1.238 millones de dólares (lo que da una variación promedio anual del 33\%), la producción cayó sólo en 211 millones. Esto significa que esta rama, que pasó de exportar a Brasil el 8\% de su producción en 2011 al 1\% en 2016, logró relocalizar la producción hacia otros mercados, en particular hacia el mercado interno, dado que las exportaciones al resto del mundo también registraron una caída (Cuadro A.5 del Anexo) ${ }^{9}$. Se trata de un período que presentó marcados problemas para el sector, con una creciente demanda interna y caídas en la producción. Si bien la producción de crudo de YPF creció, entre 2011 y 2015, en 2,2 millones de $\mathrm{m}^{3}$, el aumento fue más que compensado por la reducción en la producción de 4,5 millones de $\mathrm{m}^{3}$ por parte del resto de las petroleras que actuaban en la Argentina (Barneix, 2017). Las exportaciones más afectadas fueron las de aceites livianos y preparaciones, las cuales cayeron casi en 1.000 millones de dólares (Cuadro A.5 del Anexo). La mayor caída de las exportaciones de Brasil en relación al resto del mundo llevó a que su participación sobre el total exportado pase de $82 \%$ en 2011 a $39 \%$ en 2016.

\section{Síntesis y conclusiones}

Brasil se posiciona como el mercado más importante como destino de las exportaciones argentinas, en especial de ciertos productos industriales de mayor valor agregado que la Argentina no logra colocar fácilmente en otros mercados. Pero, al presentar la economía brasileña una significativa y elevada elasticidad ingreso de las importaciones desde Argentina, las exportaciones argentinas son fuertemente afectadas por los niveles de crecimiento de dicha economía. De esta forma, tanto las perspectivas macroeconómicas como los potenciales y efectivos competidores en el mercado brasileño se tornan una amenaza para el desempeño exportador de diversos sectores argentinos.

Como hemos apreciado en este trabajo, hasta el advenimiento de la crisis internacional la economía brasileña mostraba un aceptable nivel de crecimiento económico y una fuerte penetración importadora. Sin embargo, la Argentina logró aprovechar solo parcialmente el

(9) Esto puede estar vinculado, en parte, con la caída en el precio del crudo a nivel internacional (Arroyo Peláez; Cossío Muñoz, 2015). 
fuerte crecimiento de las importaciones brasileras (pese a contar con las preferencias arancelarias del Mercosur) por la penetración de productos chinos en este mercado. En efecto, la creciente competitividad de este país en diversos sectores industriales refleja cambios profundos en la división internacional del trabajo, cuyo impacto trasciende las fronteras de la región sudamericana.

En el mencionado contexto recesivo y con la fuerte competencia de productos chinos, nuestras observaciones demuestran que casi una cuarta parte (22\%) de la caída del VBP del sector industrial argentino durante el periodo 2011-2016 se vincula con la merma de las exportaciones a Brasil. Se trata de una caída importante, a pesar de no ser el principal factor para explicar la reducción global en los niveles de producción, y de que su efecto esté concentrado en muy pocas ramas. En primer lugar se destaca la industria automotriz, por su elevado peso relativo en el entramado industrial y por su marcada dependencia del mercado brasilero. También la rama de caucho y plástico que, pese a tener un menor peso relativo en el VBP de la industria argentina, se vio muy afectada por la caída en las exportaciones al país vecino. En un segundo escalón se encuentra la rama de productos químicos, que también sufrió los efectos de la caída en las exportaciones, tanto a Brasil como al resto del mundo.

En el resto de las ramas la reducción del VBP explicada por la caída de las exportaciones a Brasil fue menor. La principal razón del declive de la producción sectorial de dichas ramas entre 2011 y 2016 debe buscarse, entonces, en las menores ventas en el mercado interno. Especialmente en el año 2016 este componente de la demanda agregada se vio afectado por la caída en el ingreso disponible y por el aumento de las importaciones en ciertos sectores sensibles (indumentaria, textil, etc.) en los que la producción nacional perdió terreno frente a la competencia externa.

Sin embargo, es destacable la importancia del mercado brasilero para la industria argentina y la alta potencialidad de ampliar ese mercado en la medida en que el 'Mercosur pueda cumplir el importante rol de ser generador de ventajas comparativas dinámicas entre sus países miembros, lo que requiere establecer estrategias de desarrollo industrial coordinadas entre los mismos. Esto tuvo lugar, hasta ahora, en sectores que presentan predominancia de empresas multinacionales, quienes aparecen como las principales beneficiarias de la liberalización del comercio regional (Bekerman; Dulcich, 2014). Se trata de la cadena automotriz, los productos químicos y de perfumería, y ciertos sectores de las cadenas agroalimentarias que explican el protagonismo del comercio exterior regional hasta el presente. El verdadero desafío es extender esa coordinación industrial a partir de estrategias público-

privadas que incorporen a otros actores sociales y permitan que el proceso de integración regional sea un verdadero instrumento de diversificación productiva y de integración social.

\section{Bibliografía}

ACTIS, E. Estrategias de desarrollo e internacionalización de capitales: pasado y presente del caso brasileño. Revista Tempo do Mundo, Instituto de Pesquisa Econômica Aplicada - IPEA, v. 1, n. 2, 2015. 
AGOSIN, M. Crecimiento y diversificación de exportaciones en economías emergentes. Revista de la Cepal, Santiago de Chile, n. 97, (LC/G.2400-P), Abr. 2009.

ARAUJO, V.; GENTIL, D. Além da macroeconomia de curto prazo: notas sobre a debilidade estrutural da economia brasileira no período recente. Revista da Sociedade Brasileira de Economia Política, n. 41, 2015.

ARROYO PELÁEZ, A.; COSSÍO MUÑOZ, F. Impacto fiscal de la volatilidad del precio del petróleo en América Latina y el Caribe. Estudio sobre las causas y las consecuencias de la caída de los precios del petróleo y análisis de opciones de política para encaminar sus impactos. Documento de Proyecto. Comisión Económica para América Latina y el Caribe - Cepal, 2015.

BALASSA, B. Exports and economic growth: further evidence. Journal of Development Economics, 5, p. 181-189, 1978.

BARBOSA-FILHO, N. Inflation targeting in Brazil: 1999-2006. International Review of Applied Economics, v. 22, n. 2, p. 187-200, Mar. 2008.

BARNEIX, P. Las retenciones como herramienta de política sectorial en el sector de hidrocarburos en el período 2002-2012. Revista Electrónica del Instituto de Investigaciones Ambrosio L. Gioja, Buenos Aires, Argentina, n. 18, p. 145-168, 2017.

BEKERMAN, M.; DULCICH, F. La inserción internacional de la Argentina. ¿Hacia un proceso de diversificación exportadora? Revista de la Cepal, n. 110, Ago. 2013.

BEKERMAN, M.; DULCICH, F. Dependencia comercial y patrones de especialización en un proceso de integración regional: el caso de Argentina y Brasil. Desarrollo Económico, v. 53, n. 211, Ene./Abr. 2014.

BEKERMAN, M.; DULCICH, F. Exportações de argentina para o Brasil nos últimos anos: ¿um problema de demanda insuficiente ou oportunidade perdida? Revista Tempo do Mundo, Brasilia, v. 3, n. 2, 2017.

BEKERMAN, M.; SIRLIN, P. Patrón de especialización y política comercial de la Argentina en los '90. Trabajos presentados en las Primeras Jornadas de Investigación en Economía. Desarrollo Económico, v. 36, p. 115-148, 1996.

BEKERMAN, M.; DULCICH, F.; MONCAUT, N. La emergencia de China y su impacto en las relaciones comerciales entre Argentina y Brasil. Revista Problemas del Desarrollo, México, n. 176 (45), Ene./Mar. 2014.

BEKERMAN, M; DULCICH, F; GAITE, P. La inserción comercial externa de la Argentina en la última década: su impacto sobre la estructura productiva. H-industri@, Año 12, n. 23, p. 115-142, 2018.

BEKERMAN, M.; DULCICH, F.; VAZQUEZ, D. Restricción externa al crecimiento de Argentina. El rol de las manufacturas industriales. Revista Problemas del Desarrollo, México, D.F. v. 46, n. 183, 2015. 
La caída de las exportaciones industriales a Brasil, ¿cuánto afectó a la producción argentina?

BRESSER-PEREIRA, L. The macroeconomic tripod and the Workers' Party administrations. Artículo preparado para el libro editado por Lauro Mattei, Mar. 2015. Disponible en: http://www.bresserpereira.org.br/view.asp?cod=6040. Acceso en: 9 Dic. 2015.

CALDERÓN, C.; CHONG, A.; STEIN, E. Trade intensity and business cycle synchronization: Are developing countries any different? Journal of International Economics, 71, p. 2-21, 2007.

CHANG, H. The political economy of industrial policy in Korea. Cambridge Journal of Economics, p. 131-157, Jun. 1993.

CHANG, H. Kicking away the ladder - The "real" history of free trade. Presentado en la Conferencia Globalization and the Myth of Free Trade. New York: New School University, 18 Abr. 2003.

DICOVSKIY, J.; KIPER, E. Comercio Argentina-Brasil: una perspectiva desagregada. Ministerio de Economía y Finanzas Públicas, 2009. (Informe Económico, n. 68).

DULCICH, F. La nueva división internacional del trabajo y su impacto en el desarrollo económico. Revista Realidad Económica, Buenos Aires, n. 296, 2015.

DULCICH, F.; OTERO, D.; CANZIAN, A. Evolución histórica, situación actual y perspectivas de la cadena automotriz a nivel global y regional: ¿son los vehículos eléctricos una oportunidad para la Argentina? Facultad Regional General Pacheco, UTN, 2018. (Documento de Trabajo del CIDIV, n. 01). Disponible en: http://www.frgp.utn.edu.ar/images/utn-frgp/scyt/ archivos/documento-trabajocidiv/documento-de-trabajo-del-cidiv.pdf. Acceso en: 13 Nov. 2018.

DURÁN LIMA, J.; LO TURCO, A. El comercio intrarregional en América Latina: patrón de especialización y potencial exportador. In: TERRA; DURÁN LIMA (Coord.). Impactos de la crisis en América Latina: ¿Hay margen para el diseño de políticas regionales? Serie Red 'Mercosur 18, 2010.

FAO - Organización de las Naciones Unidas para la Alimentación y la Agricultura. Superación del hambre y de la pobreza rural. Iniciativas brasileñas. Brasilia, 2016.

FEDER, G. On exports and economic growth. Journal of Development Economics, 12, p. 5973, 1982.

FFRENCH DAVIS, R. Ventajas comparativas dinámicas: un planteo neoestructuralista. Cuadernos de la Cepal, Santiago de Chile, n. 63, 1991.

FMI. Brazil. Selected Issues. Washington, D.C.: Fondo Monetario Internacional, 2017.

FRENKEL, R.; RAPETTI, M. Argentina's monetary and exchange rate policies after the convertibility regime collapse. CEPR-PERI, 2007. Disponible en: http://cepr.net/documents/publications/argentina_2007_04.pdf. Acceso en: 20 Ago. 2019. 
Marta Bekerman, Federico Dulcich, Pedro Gaite

HAUSMANN, R.; RODRIK, D. Economic development as self-discovery. Journal of Development Economics, Amsterdam, Elsevier, v. 72, n. 2, 2003.

HEYMANN, D.; NAVAJAS, F. Coordinación de políticas macroeconómicas en 'Mercosur: algunas reflexiones. In: ENSAYOS sobre la inserción regional de la Argentina. Buenos Aires: Cepal, 1998. (Documento de Trabajo, n. 81).

INDEC. Intercambio Comercial Argentino. Datos provisorios de los años 2014 y 2015. Buenos Aires: Instituto Nacional de Estadísticas y Censos - INDEC, Feb. 2016.

INDEC. Intercambio Comercial Argentino. Cifras estimadas de julio de 2017. Comercio Exterior, Instituto Nacional de Estadísticas y Censos - INDEC, Buenos Aires, v. 1, n. 13, Ago. $2017 \mathrm{a}$

INDEC. Intercambio Comercial Argentino. Cifras estimadas de diciembre de 2016. Comercio Exterior, Instituto Nacional de Estadísticas y Censos - INDEC, Buenos Aires, v. 1, n. 9, Ene. $2017 \mathrm{~b}$.

KRUGMAN, P. Increasing returns, monopolistic competition and international trade. Journal of International Economics, North-Holland Publishing Company, n. 9, p. 469-479, 1979.

KRUGMAN, P. Scale economies, product differentiation, and the pattern of trade. The American Economic Review, v. 70, n. 5, 1980.

MANZANO, M.; SALAS, C. Desarrollo al filo de la navaja: economía y trabajo en Brasil: 1995-2014. Revista de Economía Crítica, n. 21, 2016.

MARIN, D. Is the export-led growth hypothesis valid for industrialized countries? The Review of Economics and Statistics, v. 74, n. 4, p. 678-688, 1992.

MELLO, G.; ROSSI, P. Componentes macroeconômicos e estruturais da crise brasileira: o subdesenvolvimento revisitado. Brazilian Keynesian Review, v. 2, n. 2, p. 252-263, 2016.

NEFFA, J. Modos de desarrollo, trabajo y empleo en la Argentina (2002-2017). Revista Estado y Políticas Públicas, n. 9, p. 93-119, 2017.

OREIRO, J. A grande recessão brasileira: diagnóstico e uma agenda de política económica, Estudos Avançados, São Paulo, v. 31, n. 89, 2017.

PRASAD, E. International trade and the business cycle. The Economic Journal, 109, p. 588606, 1999.

PROTEGER. Importaciones de la cadena de valor textil y confecciones. Resumen ejecutivo. Buenos Aires, Argentina, 2017.

RODRIGO OCTÁVIO, O. Investimento público no Brasil: trajetória e relações com o regime fiscal. Brasília: Instituto de Pesquisa Econômica Aplicada - Ipea, 2016. (Texto para Discussão, n. 2215). 
RODRIK, D. Políticas de diversificación económica. Revista de la Cepal, n. 87 (LC/G.2287P), Santiago de Chile, Dic. 2005.

SERRANO, F.; SUMMA, R. Aggregate demand and the slowdown of Brazilian economic growth from 2011-2014. Center for Economic and Policy Research - CEPR, Ago. 2015. Disponible en: http://www.cepr.net/documents/publications/Brazil-2015-08.pdf. Acceso en: 17 Sept. 2015.

SIRLIN, P. El régimen de especialización industrial argentino: ¿política industrial de nueva generación o mera transferencia de recursos? Revista de la Cepal, Santiago de Chile, n. 68, 1999.

WADE, R. What can economics learn from East Asian success? Annals of the American Academy of Political and Social Science, Thousand Oaks, Sage Publications, v. 505, 1989. 


\section{Anexo Estadístico}

Gráfico A.1

Participación de Brasil como destino de exportación de Argentina y de Argentina como proveedor del mercado de importación de Brasil

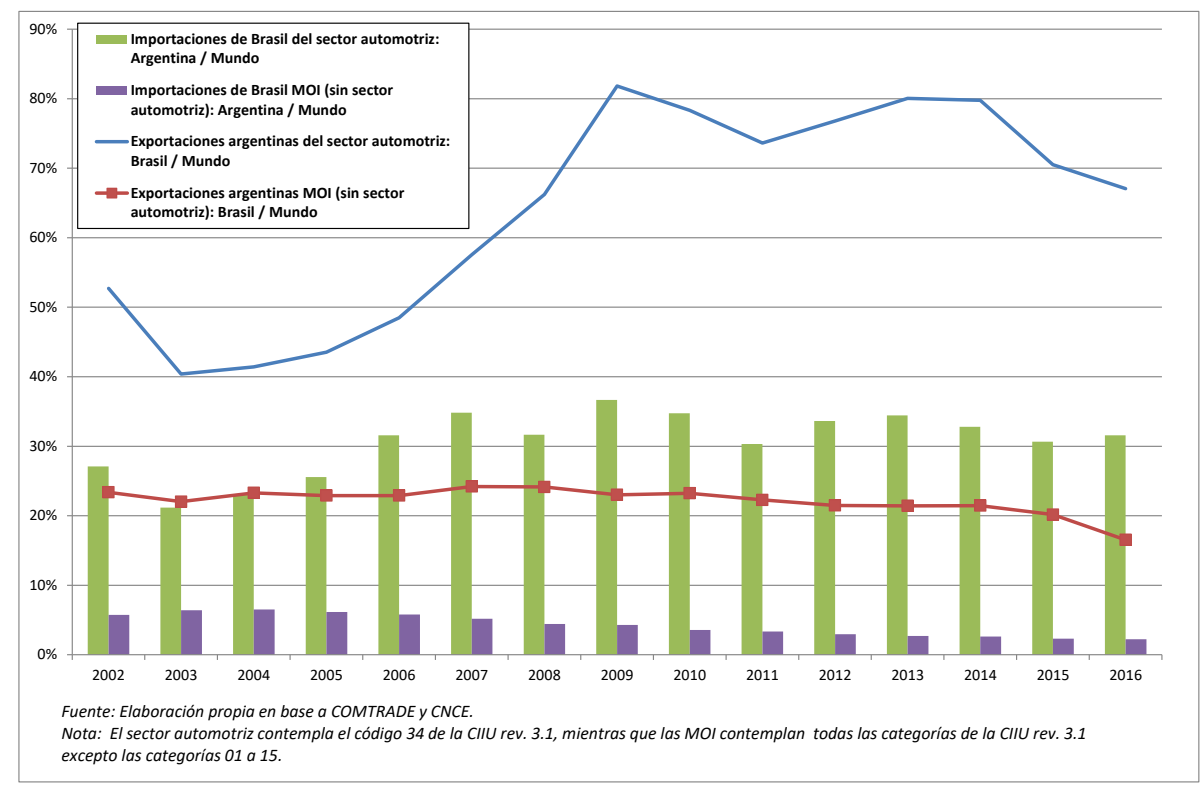

Gráfico A.2

Tasa de interés, variación del tipo de cambio nominal y componentes seleccionados de la balanza de pagos de Brasil

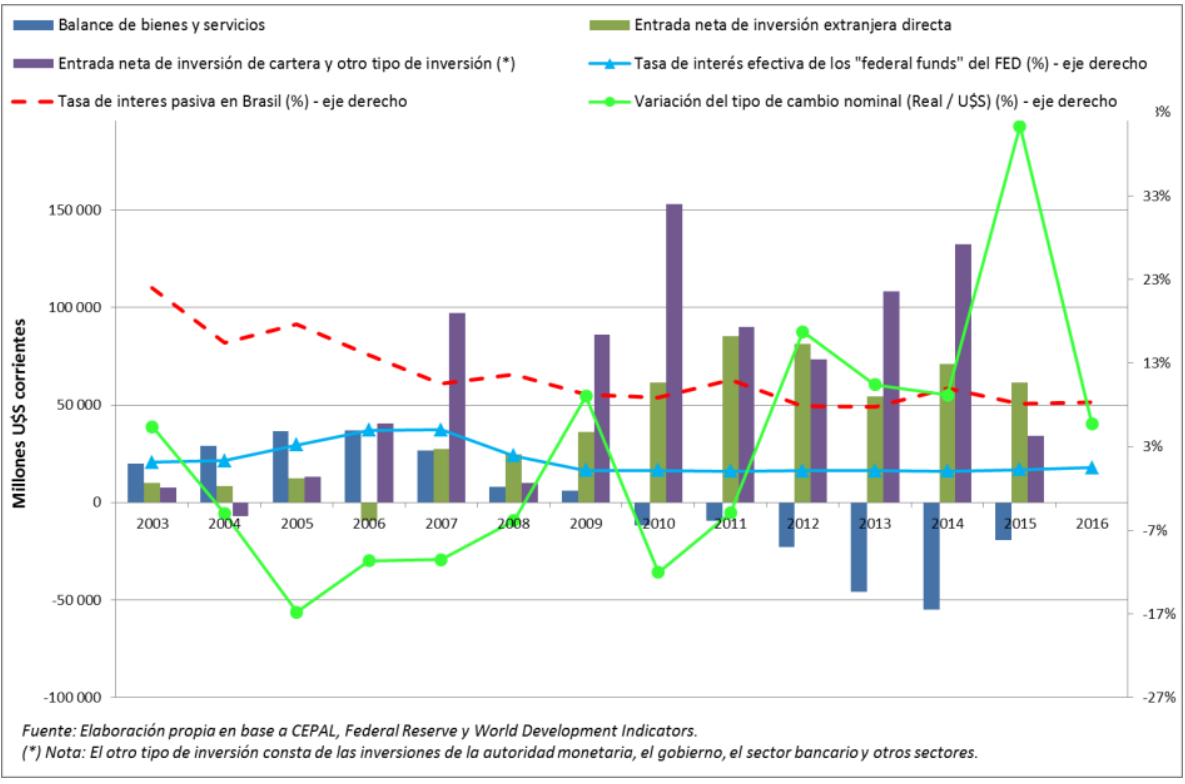


Cuadro A.1

Variación lineal del VBP, el consumo interno, las exportaciones a Brasil y al resto del mundo según rama industrial, para períodos seleccionados. Millones de dólares constantes de 2011

\begin{tabular}{|c|c|c|c|c|c|c|c|c|c|c|c|c|}
\hline & \multicolumn{4}{|c|}{$\begin{array}{c}\text { Variación lineal 2011-2016 (Mill. U\$S } \\
\text { constantes de 2011) }\end{array}$} & \multicolumn{4}{|c|}{$\begin{array}{c}\text { Variación lineal 2011-2013 (Mill. U\$S } \\
\text { constantes de 2011) }\end{array}$} & \multicolumn{4}{|c|}{$\begin{array}{c}\text { Variación lineal 2013-2016 (Mill. U\$S } \\
\text { constantes de 2011) }\end{array}$} \\
\hline & VBP & $\begin{array}{c}\text { Consumo } \\
\text { interno }\end{array}$ & X Brasil & X RdM & VBP & $\begin{array}{c}\text { Consumo } \\
\text { interno }\end{array}$ & X Brasil & X RdM & VBP & $\begin{array}{c}\text { Consumo } \\
\text { interno }\end{array}$ & X Brasil & X RdM \\
\hline 15 - Alimentos y bebidas & -5460 & -282 & -579 & -4.600 & 6333 & 7.796 & -278 & -1.185 & -11793 & -8.077 & -300 & -3.415 \\
\hline 16 - Tabaco & -92 & -92 & 0 & 1 & 3 & -2 & 0 & 5 & -95 & -90 & 0 & -5 \\
\hline 17 - Textiles & -1164 & -922 & -74 & -169 & -241 & -96 & -37 & -108 & -923 & -826 & -37 & -60 \\
\hline 18 - Prendas de vestir & -1802 & -1.734 & -12 & -57 & 569 & 586 & 6 & -22 & -2371 & -2.320 & -17 & -34 \\
\hline 19 - Curtido de cueros y marroq & -1203 & -912 & -5 & -287 & -53 & -8 & 3 & -47 & -1151 & -904 & -8 & -239 \\
\hline 20 - Madera & -950 & -821 & -53 & -76 & 67 & 116 & -28 & -21 & -1017 & -937 & -25 & -55 \\
\hline 21 - Papel & -428 & -94 & -95 & -238 & 368 & 513 & -40 & -105 & -796 & -607 & -55 & -133 \\
\hline 22 - Edición e impresión & -1333 & -1.265 & -4 & -65 & 333 & 370 & 0 & -37 & -1667 & -1.635 & -4 & -27 \\
\hline 23- Refinación de petroleo & -211 & 1.735 & -1.238 & -708 & 2912 & 3.796 & -709 & -175 & -3123 & -2.062 & -529 & -533 \\
\hline 24 - Prod. químicos & -2264 & 40 & -705 & -1.599 & 3003 & 4.376 & -77 & -1.295 & -5268 & -4.336 & -628 & -303 \\
\hline 25 - Caucho y plástico & -334 & 76 & -226 & -184 & 1240 & 1.361 & -71 & -49 & -1574 & -1.284 & -155 & -134 \\
\hline 26 - Prod. minerales no metalicos & -1116 & -988 & -35 & -93 & 751 & 803 & -18 & -34 & -1867 & -1.791 & -16 & -59 \\
\hline 27 - Metales comunes & -5657 & -3.509 & -308 & -1.840 & -865 & 380 & -55 & -1.190 & -4792 & -3.889 & -254 & -650 \\
\hline 28 - Productos de metal & -2898 & -2.647 & -91 & -160 & -155 & -63 & -28 & -64 & -2743 & -2.584 & -63 & -96 \\
\hline 29 - Maquinaria y equipo & -2790 & -1.848 & -259 & -683 & 364 & 643 & -97 & -182 & -3154 & -2.491 & -162 & -501 \\
\hline 30 - Computadoras y maquinaria de oficina & -102 & -94 & -1 & -7 & -59 & -68 & 3 & 6 & -43 & -26 & -4 & -13 \\
\hline 31 - Maquinaria y aparatos eléctricos & -737 & -422 & -117 & -198 & -47 & 97 & -56 & -88 & -690 & -519 & -60 & -110 \\
\hline 32 - Radio, TV, y equipos de comunicaciones & -319 & -288 & -17 & -14 & 1222 & 1.237 & -6 & -9 & -1541 & -1.525 & -11 & -5 \\
\hline 33 - Instrumentos médicos y ópticos & -288 & -182 & -49 & -56 & 41 & 93 & -24 & -29 & -328 & -276 & -25 & -27 \\
\hline 34 - Automotriz y autopartes & -6970 & -1.658 & -4.232 & -1.080 & 1321 & 1.382 & 611 & -671 & -8291 & -3.040 & -4.842 & -409 \\
\hline 35- Equipo de transporte & -369 & 173 & -84 & -458 & 48 & 339 & -42 & -248 & -417 & -166 & -42 & -209 \\
\hline 36 - Muebles & -932 & -855 & -12 & -65 & 284 & 316 & -6 & -26 & -1216 & -1.171 & -6 & -39 \\
\hline TOTAL INDUSTRIAL & -37418 & $\begin{array}{l}-16589 \\
\end{array}$ & $\begin{array}{ll}-8194 \\
\end{array}$ & $\begin{array}{l}-12635 \\
\end{array}$ & 17441 & 23967 & -950 & -5576 & -54858 & -40556 & $\begin{array}{l}-7244 \\
\end{array}$ & -7058 \\
\hline
\end{tabular}

Fuente: elaboración propia en base a INDEC y Comtrade. 
Marta Bekerman, Federico Dulcich, Pedro Gaite

Cuadro A.2

Exportaciones a Brasil y al resto del mundo para las ramas en las que el impacto de Brasil es "significativo" y la caída en la producción considerable (cuadrante A). 2011-2016.

\begin{tabular}{|c|c|c|c|c|c|c|c|c|c|c|}
\hline \multirow{2}{*}{$\begin{array}{c}\text { CIIU } \\
\text { Rev. } 3 \\
\text { (2 dig.) } \\
- \\
\text { HS2002 } \\
\text { (6 dig.) }\end{array}$} & \multirow[b]{2}{*}{ Descripción } & \multicolumn{3}{|c|}{$\begin{array}{l}\text { Exportaciones a Brasil } \\
\text { (Mill. U\$S } \\
\text { constantes de 2011) }\end{array}$} & \multicolumn{3}{|c|}{$\begin{array}{l}\text { Exportaciones al mundo } \\
\text { (Mill. U\$S } \\
\text { constantes de 2011) } \\
\end{array}$} & \multicolumn{3}{|c|}{$\begin{array}{l}\text { Exportaciones a Brasil / } \\
\text { Exportaciones al mundo (\%) }\end{array}$} \\
\hline & & 2011 & 2016 & \begin{tabular}{|c|} 
Var. \\
Prom. \\
anual \\
2011-2016
\end{tabular} & 2011 & 2016 & \begin{tabular}{|c|} 
Var. \\
Prom. \\
anual \\
$2011-2016$
\end{tabular} & 2011 & 2016 & $\begin{array}{c}\text { Variación } \\
\text { lineal } \\
\text { 2011-2016 }\end{array}$ \\
\hline 34 & $\begin{array}{l}\text { Fabricación de vehículos automotores, remolques y } \\
\text { semirremolques }\end{array}$ & 7.524 & 3.292 & $-15 \%$ & 10.220 & 4.908 & $-14 \%$ & $74 \%$ & $67 \%$ & $-7 \%$ \\
\hline 870321 & De cilindrada inferior o igual a $1.000 \mathrm{~cm} 3$ & 912 & 207 & $-26 \%$ & 914 & 207 & $-26 \%$ & $100 \%$ & $100 \%$ & $0 \%$ \\
\hline 870323 & $\begin{array}{l}\text { De cilindrada superior a } 1.500 \mathrm{~cm} 3 \text { pero inferior o igual a } \\
3.000 \mathrm{~cm} 3\end{array}$ & 1.796 & 439 & $-25 \%$ & 1.927 & 473 & $-24 \%$ & $93 \%$ & $93 \%$ & $0 \%$ \\
\hline 870421 & De peso total con carga maxima, inferior o igual a $5 \mathrm{t}$. & 1.666 & 1.243 & $-6 \%$ & 3.010 & 2.130 & $-7 \%$ & $55 \%$ & $58 \%$ & $3 \%$ \\
\hline 24 & Fabricación de sustancias y productos químicos & 1.832 & 1.127 & $-9 \%$ & 7.453 & 5.149 & $-7 \%$ & $25 \%$ & $22 \%$ & $-3 \%$ \\
\hline 330720 & Desodorantes corporales y antitranspirantes & 184 & 102 & $-11 \%$ & 333 & 182 & $-11 \%$ & $55 \%$ & $56 \%$ & $1 \%$ \\
\hline 390120 & Polietileno de densidad igual o superior a 0,94 & 104 & 105 & $0 \%$ & 137 & 128 & $-1 \%$ & $76 \%$ & $82 \%$ & $5 \%$ \\
\hline 390190 & Los demas polímeros de etileno en formas primarias & 125 & 128 & $0 \%$ & 142 & 146 & $0 \%$ & $88 \%$ & $88 \%$ & $0 \%$ \\
\hline 21 & Fabricación de papel y de productos de papel & 202 & 107 & $-12 \%$ & 650 & 317 & $-13 \%$ & $31 \%$ & $34 \%$ & $3 \%$ \\
\hline 470321 & $\begin{array}{l}\text { Pasta quimica de madera a la sosa (soda) o al sulfato, } \\
\text { excepto la pasta para disolver }\end{array}$ & 115 & 86 & $-6 \%$ & 167 & 104 & $-9 \%$ & $69 \%$ & $83 \%$ & $14 \%$ \\
\hline 481840 & $\begin{array}{l}\text { Compresas y tampones higiénicos, y artículos higiénicos } \\
\text { similares }\end{array}$ & 15 & 1 & $-40 \%$ & 141 & 45 & $-20 \%$ & $11 \%$ & $3 \%$ & $-8 \%$ \\
\hline 482312 & Papel engomado o adhesivo, en tiras o en bobinas (rollos) & 0 & 4 & n.c. & 0 & 11 & n.c. & n.c. & $35 \%$ & n.c. \\
\hline 33 & $\begin{array}{l}\text { Fabricación de instrumentos médicos, ópticos y de } \\
\text { precisión; fabricación de relojes }\end{array}$ & 76 & 27 & $-19 \%$ & 224 & 119 & $-12 \%$ & $34 \%$ & $23 \%$ & $-11 \%$ \\
\hline 901920 & $\begin{array}{l}\text { Aparatos de ozonoterapia, oxigenoterapia o } \\
\text { aerosolterapia, aparatos respiratorios de reanimación y } \\
\text { demas aparatos de terapia respiratoria }\end{array}$ & 7 & 2 & $-19 \%$ & 18 & 10 & $-10 \%$ & $37 \%$ & $22 \%$ & $-15 \%$ \\
\hline 902920 & Velocímetros y tacómetros; estroboscópios & 0 & 2 & $113 \%$ & 0 & 2 & $40 \%$ & $11 \%$ & $92 \%$ & $80 \%$ \\
\hline 903289 & $\begin{array}{l}\text { Instrumentos y aparatos para regulación o control } \\
\text { automáticos }\end{array}$ & 37 & 4 & $-34 \%$ & 46 & 9 & $-28 \%$ & $80 \%$ & $50 \%$ & $-30 \%$ \\
\hline 31 & $\begin{array}{l}\text { Fabricación de maquinaria y aparatos eléctricos } \\
\text { n.c.p. }\end{array}$ & 144 & 28 & $-28 \%$ & 447 & 132 & $-22 \%$ & $32 \%$ & $21 \%$ & $-11 \%$ \\
\hline 850140 & $\begin{array}{l}\text { Motores y generadores electricos, excepto los grupos } \\
\text { electrógenos }\end{array}$ & 7 & 4 & $-10 \%$ & 7 & 4 & $-11 \%$ & $94 \%$ & $97 \%$ & $3 \%$ \\
\hline 853710 & $\begin{array}{l}\text { Cuadros, paneles, consolas, etc. para una tensión inferior } \\
\text { o igual a } 1.000 \mathrm{~V} \text {. }\end{array}$ & 10 & 3 & $-19 \%$ & 38 & 17 & $-15 \%$ & $26 \%$ & $20 \%$ & $-6 \%$ \\
\hline 854430 & $\begin{array}{l}\text { Cables para bujías de encendido o del tipo de los } \\
\text { utilizados en los medios de transporte }\end{array}$ & 7 & 3 & $-16 \%$ & 9 & 4 & $-16 \%$ & $79 \%$ & $82 \%$ & $3 \%$ \\
\hline & TOTAL & 9.778 & 4.580 & $-14 \%$ & 18.994 & 10.624 & $-11 \%$ & $51 \%$ & $43 \%$ & $-8 \%$ \\
\hline
\end{tabular}

\section{Cuadro A.3}

Exportaciones a Brasil y al resto del mundo para la rama en la que el impacto de Brasil es "significativo" y la caída en la producción menor (cuadrante B). 2011-2016

\begin{tabular}{|c|c|c|c|c|c|c|c|c|c|c|}
\hline \multirow{2}{*}{\begin{tabular}{|c|} 
CIIU \\
Rev. 3 \\
(2 dig.) \\
- \\
HS2002 \\
(6 dig.)
\end{tabular}} & \multirow[b]{2}{*}{ Descripción } & \multicolumn{3}{|c|}{$\begin{array}{c}\text { Exportaciones a Brasil } \\
\text { (Mill. U\$S } \\
\text { constantes de 2011) } \\
\end{array}$} & \multicolumn{3}{|c|}{$\begin{array}{c}\text { Exportaciones al mundo } \\
\text { (Mill. U\$S } \\
\text { constantes de 2011) }\end{array}$} & \multicolumn{3}{|c|}{$\begin{array}{c}\text { Exportaciones a Brasil / } \\
\text { Exportaciones al mundo (\%) }\end{array}$} \\
\hline & & 2011 & 2016 & $\begin{array}{c}\text { Var. } \\
\text { Prom. } \\
\text { anual } \\
2011-2016\end{array}$ & 2011 & 2016 & \begin{tabular}{|c|} 
Var. \\
Prom. \\
anual \\
$2011-2016$
\end{tabular} & 2011 & 2016 & $\begin{array}{c}\text { Variación } \\
\text { lineal } \\
\text { 2011-2016 }\end{array}$ \\
\hline 25 & Fabricación de productos de caucho y plástico & 449 & 223 & $-13 \%$ & 937 & 527 & $-11 \%$ & $48 \%$ & $42 \%$ & $-6 \%$ \\
\hline 392010 & $\begin{array}{l}\text { Placas de plastico no celular y sin refuerzo de otrasa } \\
\text { materias }\end{array}$ & 42 & 24 & $-10 \%$ & 100 & 52 & $-12 \%$ & $42 \%$ & $47 \%$ & $5 \%$ \\
\hline 392330 & Botellas, frascos y artículos similares de plástico & 42 & 10 & $-25 \%$ & 59 & 23 & $-17 \%$ & $71 \%$ & $42 \%$ & $-29 \%$ \\
\hline 401110 & $\begin{array}{l}\text { Neumaticos de caucho del tipo de los utilizados en } \\
\text { automóviles de turismo }\end{array}$ & 120 & 71 & $-10 \%$ & 170 & 102 & $-10 \%$ & $70 \%$ & $69 \%$ & $-1 \%$ \\
\hline & TOTAL & 449 & 223 & $-13 \%$ & 937 & 527 & $-11 \%$ & $48 \%$ & $42 \%$ & $-6 \%$ \\
\hline
\end{tabular}


Cuadro A.4

Exportaciones a Brasil y al resto del mundo para ramas seleccionadas en las que el impacto de Brasil es "poco significativo" y la caída en la producción considerable (cuadrante C). 2011-2016

\begin{tabular}{|c|c|c|c|c|c|c|c|c|c|c|}
\hline \multirow{2}{*}{$\begin{array}{c}\text { ClIU } \\
\text { Rev. } 3 \\
\text { (2 dig.) } \\
- \\
\text { HS2002 } \\
\text { (6 dig.) }\end{array}$} & \multirow[b]{2}{*}{ Descripción } & \multicolumn{3}{|c|}{$\begin{array}{l}\text { Exportaciones a Brasil } \\
\text { (Mill. U\$S } \\
\text { constantes de 2011) }\end{array}$} & \multicolumn{3}{|c|}{$\begin{array}{l}\text { Exportaciones al mundo } \\
\text { (Mill. U\$S } \\
\text { constantes de 2011) }\end{array}$} & \multicolumn{3}{|c|}{$\begin{array}{l}\text { Exportaciones a Brasil / } \\
\text { Exportaciones al mundo (\%) }\end{array}$} \\
\hline & & 2011 & 2016 & \begin{tabular}{|c|} 
Var. \\
Prom. \\
anual \\
2011-2016
\end{tabular} & 2011 & 2016 & $\begin{array}{c}\begin{array}{c}\text { Var. } \\
\text { Prom. } \\
\text { anual } \\
2011-2016\end{array} \\
\end{array}$ & 2011 & 2016 & $\begin{array}{c}\text { Variación } \\
\text { lineal } \\
\text { 2011-2016 }\end{array}$ \\
\hline 15 & Elaboración de productos alimenticios y bebidas & 1.749 & 1.171 & $-8 \%$ & 26.349 & 21.171 & $-4 \%$ & $7 \%$ & $6 \%$ & $-1 \%$ \\
\hline 110100 & Harina de trigo o de morcajo & 278 & 91 & $-20 \%$ & 387 & 165 & $-16 \%$ & $72 \%$ & $55 \%$ & $-17 \%$ \\
\hline 110710 & Malta (de cebada u otros cereales) & 170 & 184 & $2 \%$ & 234 & 234 & $0 \%$ & $73 \%$ & $79 \%$ & $6 \%$ \\
\hline 200410 & Papas preparadas o congeladas & 128 & 138 & $1 \%$ & 166 & 166 & $0 \%$ & $77 \%$ & $83 \%$ & $6 \%$ \\
\hline 29 & Fabricación de maquinaria y equipo n.c.p. & 449 & 190 & $-16 \%$ & 1.655 & 714 & $-15 \%$ & $27 \%$ & $27 \%$ & $0 \%$ \\
\hline 841899 & $\begin{array}{l}\text { Refrigeradores, congeladores y demas material para } \\
\text { produccion de frio }\end{array}$ & 14 & 16 & $3 \%$ & 24 & 19 & $-5 \%$ & $56 \%$ & $85 \%$ & $28 \%$ \\
\hline 848210 & Rodamientos de bolas, rodillos o agujas & 30 & 11 & $-18 \%$ & 52 & 21 & $-17 \%$ & $59 \%$ & $53 \%$ & $-5 \%$ \\
\hline 848340 & Engranajes y ruedas de fricción & 13 & 16 & $5 \%$ & 24 & 20 & $-4 \%$ & $52 \%$ & $83 \%$ & $31 \%$ \\
\hline 17 & Fabricación de productos textiles & 110 & 36 & $-20 \%$ & 463 & 221 & $-14 \%$ & $24 \%$ & $16 \%$ & $-7 \%$ \\
\hline 520523 & Hilados sencillos de fibras peinadas y algodón & 8 & 2 & $-22 \%$ & 8 & 2 & $-22 \%$ & $98 \%$ & $99 \%$ & $1 \%$ \\
\hline 560311 & Tela sin tejer de peso inferior o igual a $25 \mathrm{~g} / \mathrm{m} 2$ & 29 & 21 & $-6 \%$ & 50 & 26 & $-12 \%$ & $58 \%$ & $82 \%$ & $23 \%$ \\
\hline 560312 & $\begin{array}{l}\text { Tela sin tejer de peso superior a } 25 \mathrm{~g} / \mathrm{m} 2 \text { pero inferior o } \\
\text { igual a } 70 \mathrm{~g} / \mathrm{m} 2\end{array}$ & 4 & 1 & $-26 \%$ & 11 & 4 & $-16 \%$ & $40 \%$ & $22 \%$ & $-18 \%$ \\
\hline 20 & $\begin{array}{l}\text { Producción de madera y fabricación de productos de } \\
\text { madera y corcho, excepto muebles; fabricación de } \\
\text { artículos de paja y de materiales trenzables }\end{array}$ & 56 & 3 & $-46 \%$ & 211 & 83 & $-17 \%$ & $26 \%$ & $3 \%$ & $-23 \%$ \\
\hline 440710 & $\begin{array}{l}\text { Madera de coniferas aserrada o desbastada } \\
\text { Iongitudinalmente, de espesor superior a } 6 \mathrm{~mm}\end{array}$ & 3 & 1 & $-21 \%$ & 35 & 22 & $-8 \%$ & $8 \%$ & $4 \%$ & $-4 \%$ \\
\hline 441129 & $\begin{array}{l}\text { Tableros de fibra de masa volzmica superior a } 0,5 \mathrm{~g} / \mathrm{cm} 3 \\
\text { pero inferior o igual a } 0,8 \mathrm{~g} / \mathrm{cm} 3 \text {. }\end{array}$ & 50 & 0 & $-100 \%$ & 84 & 0 & $-100 \%$ & $60 \%$ & n.c. & n.c. \\
\hline 441139 & $\begin{array}{l}\text { Tableros de fibra de masa volzmica superior a 0,35 } \\
\mathrm{g} / \mathrm{cm} 3 \text { pero inferior o igual a } 0,5 \mathrm{~g} / \mathrm{cm} 3\end{array}$ & 0 & 0 & n.c. & 0 & 26 & n.c. & n.c. & $0 \%$ & n.c. \\
\hline 27 & Fabricación de metales comunes & 470 & 162 & $-19 \%$ & 5.103 & 2.955 & $-10 \%$ & $9 \%$ & $5 \%$ & $-4 \%$ \\
\hline 760110 & Aluminio sin alear & 115 & 33 & $-22 \%$ & 407 & 304 & $-6 \%$ & $28 \%$ & $11 \%$ & $-17 \%$ \\
\hline 760120 & Aleaciones de aluminio & 73 & 44 & $-9 \%$ & 255 & 166 & $-8 \%$ & $29 \%$ & $27 \%$ & $-2 \%$ \\
\hline 760511 & $\begin{array}{l}\text { Alambre de aluminio sin alear con la mayor dimensión de } \\
\text { la sección transversal superior a } 7 \mathrm{~mm}\end{array}$ & 37 & 29 & $-5 \%$ & 61 & 61 & $0 \%$ & $60 \%$ & $47 \%$ & $-13 \%$ \\
\hline 28 & $\begin{array}{l}\text { Fabricación de productos elaborados de metal, } \\
\text { excepto maquinaria y equipo }\end{array}$ & 158 & 67 & $-16 \%$ & 459 & 208 & $-15 \%$ & $34 \%$ & $32 \%$ & $-2 \%$ \\
\hline 731210 & $\begin{array}{l}\text { Cables y artículos similares, de hierro o acero, sin aislar } \\
\text { para elctricidad }\end{array}$ & 17 & 5 & $-21 \%$ & 33 & 14 & $-16 \%$ & $50 \%$ & $38 \%$ & $-12 \%$ \\
\hline 732690 & Las demas manufacturas de hierro o acero & 58 & 24 & $-16 \%$ & 100 & 50 & $-13 \%$ & $58 \%$ & $48 \%$ & $-10 \%$ \\
\hline 761699 & Las demas manufacturas de aluminio & 2 & 13 & $45 \%$ & 10 & 19 & $14 \%$ & $21 \%$ & $70 \%$ & $49 \%$ \\
\hline 26 & Fabricación de productos minerales no metálicos & 46 & 11 & $-25 \%$ & 271 & 143 & $-12 \%$ & $17 \%$ & $8 \%$ & $-9 \%$ \\
\hline 680422 & Muelas y artículos similares, sin bastidor & 4 & 3 & $-1 \%$ & 8 & 7 & $-3 \%$ & $46 \%$ & $51 \%$ & $4 \%$ \\
\hline 680710 & $\begin{array}{l}\text { Manufacturas de asfalto o de productos similares, en } \\
\text { rollos }\end{array}$ & 13 & 2 & $-32 \%$ & 25 & 12 & $-14 \%$ & $52 \%$ & $17 \%$ & $-35 \%$ \\
\hline 680911 & $\begin{array}{l}\text { Placas, hojas, paneles, revestidos o reforzados } \\
\text { exclusivamente con papel o cartón }\end{array}$ & 10 & 0 & $-100 \%$ & 28 & 15 & $-11 \%$ & $35 \%$ & $0 \%$ & $-35 \%$ \\
\hline & TOTAL & 3.038 & 1.640 & $-12 \%$ & 34.511 & 25.494 & $-6 \%$ & $9 \%$ & $6 \%$ & $-2 \%$ \\
\hline
\end{tabular}

Cuadro A.5

Exportaciones a Brasil y al resto del mundo para el caso particular de la rama de fabricación de coque, productos de la refinación del petróleo y combustible nuclear. 2011-2016.

\begin{tabular}{|c|c|c|c|c|c|c|c|c|c|c|}
\hline \multirow{2}{*}{$\begin{array}{l}\text { ClIU Rev. } 3 \\
\text { (2 dig.) - } \\
\text { HS2002 (6 } \\
\text { dig.) }\end{array}$} & \multirow{2}{*}{ Descripción } & \multicolumn{3}{|c|}{$\begin{array}{l}\text { Exportaciones a Brasil } \\
\text { (Mill. U\$S } \\
\text { constantes de 2011) }\end{array}$} & \multicolumn{3}{|c|}{$\begin{array}{l}\text { Exportaciones al mundo } \\
\text { (Mill. U\$S } \\
\text { constantes de 2011) }\end{array}$} & \multicolumn{3}{|c|}{$\begin{array}{c}\text { Exportaciones a Brasil / } \\
\text { Exportaciones al mundo (\%) }\end{array}$} \\
\hline & & 2011 & 2016 & \begin{tabular}{|c|} 
Var. Prom. \\
anual \\
2011-2016
\end{tabular} & 2011 & 2016 & \begin{tabular}{|c|} 
Var. Prom. \\
anual \\
2011-2016 \\
\end{tabular} & 2011 & 2016 & $\begin{array}{l}\text { Variación } \\
\text { lineal } \\
\text { 2011-2016 } \\
\end{array}$ \\
\hline 23 & $\begin{array}{l}\text { Fabricación de coque, productos de } \\
\text { la refinación del petróleo y } \\
\text { combustible nuclear }\end{array}$ & 1.439 & 201 & $-33 \%$ & 2.520 & 574 & $-26 \%$ & $57 \%$ & $35 \%$ & $-22 \%$ \\
\hline 271011 & Aceites livianos y preparaciones & 1.057 & 102 & $-37 \%$ & 1.282 & 263 & $-27 \%$ & $82 \%$ & $39 \%$ & $-44 \%$ \\
\hline 271112 & $\begin{array}{l}\text { Propano. Licuados. Gas de petróleo y } \\
\text { demás hidrocarburos gaseosos }\end{array}$ & 181 & 67 & $-18 \%$ & 397 & 124 & $-21 \%$ & $46 \%$ & $54 \%$ & $8 \%$ \\
\hline 271113 & $\begin{array}{l}\text { Butanos, licuados, gas de petroleo y } \\
\text { demas hidrocarburos gaseosos }\end{array}$ & 118 & 27 & $-26 \%$ & 286 & 94 & $-20 \%$ & $41 \%$ & $29 \%$ & $-13 \%$ \\
\hline & TOTAL & 1.439 & 201 & $-33 \%$ & 2.520 & 574 & $-26 \%$ & $57 \%$ & $35 \%$ & $-22 \%$ \\
\hline
\end{tabular}




\section{Anexo Metodológico}

\section{Fuentes utilizadas}

Los datos de comercio internacional sectoriales de los distintos gráficos y tablas son fuente COMTRADE, de Naciones Unidas. Están valuados en dólares estadounidenses del año 2011, utilizando el deflactor del PBI de EEUU (fuente World Development Indicators, del Banco Mundial) para deflactarlos. Poseen valuación FOB para las exportaciones y CIF para las importaciones.

Los datos macroeconómicos del Gráfico 1 son fuente Fondo Monetario Internacional, con datos observados hasta 2016 y proyecciones a partir de 2017.

Los datos de VBP y VAB sectoriales de la Argentina son fuente INDEC, que los presenta en pesos argentinos corrientes. Hay sido transformados a dólares estadounidenses del año 2011 mediante el tipo de cambio (entre el peso argentino y el dólar) y el deflactor del PBI de EEUU fuente World Development Indicators, del Banco Mundial.

\section{Clasificaciones sectoriales}

Los datos sectoriales de VBP y VAB de la Argentina están clasificados en la fuente INDEC a dos dígitos de la Clasificación Industrial Internacional Uniforme -CIIU-, revisión 3; que es la utilizada en el trabajo. Los datos de comercio internacional sectoriales se obtuvieron de COMTRADE a seis dígitos de la clasificación Harmonized System 2002 (HSO2). La transformación de estos datos a la clasificación CIIU rev. 3 utilizada en el trabajo se realizó mediante la Matriz de Correspondencias de la Comisión Nacional de Comercio Exterior (CNCE) de la Argentina. 